\title{
EL JUEZ NACIONAL DE MEDIDAS CAUTELARES Y LA TUTELA DEL ORDEN PÚBLICO Y DEL INTERÉS PÚBLICO DE LA UNIÓN EUROPEA
}

\author{
CARLOS J. MOREIRO GONZÁLEZ1
}

Cómo citar/Citation

Moreiro González, C. J. (2016). El juez nacional de medidas cautelares y la tutela del órden público y del interés público de la Unión Europea.

Revista de Derecho Comunitario Europeo, 54, 473-516

doi: http://dx.doi.org/10.18042/cepc/rdce.54.02

\section{Resumen}

El Tribunal de Justicia de la Unión Europea ha establecido durante los últimos años una jurisprudencia mediante la cual refuerza la función esencial de los órganos jurisdiccionales de los Estados miembros como jueces ordinarios del derecho de la Unión, al atribuirles ciertas potestades para la adopción de medidas cautelares cuando esté en juego la tutela del orden público y del interés público de la Unión Europea.

Se trata de un fenómeno novedoso por cuanto agrava el deber de diligencia que corresponde al juez nacional de medidas cautelares, ya que, junto con la obligación de garantizar el efecto útil de las disposiciones y principios de que se trate, tiene así mismo la obligación de evitar que se violen dichas disposiciones y principios, dado que son elementos fundamentales del sistema jurídico de la Unión Europea y deben de protegerse íntegramente en todo el territorio de sus Estados miembros.

El conjunto de decisiones relevantes del Tribunal de Justicia que articula el régimen de la mencionada atribución de la potestad cautelar a favor de los jueces nacionales se caracteriza por su dinamismo, su elevada precisión técnica y porque suele tener un cierto componente didáctico.

1 Catedrático de Derecho Internacional Público. Cátedra Jean Monnet «ad personam» de Derecho de la UE. Facultad de Ciencias Sociales y Jurídicas de la Universidad Carlos III de Madrid. 
Esta doctrina tiene un común denominador que preserva el equilibrio entre la necesaria protección del efecto útil del derecho de la Unión y el respeto a la autonomía del juez nacional que debe garantizar el ejercicio del derecho a la tutela judicial efectiva.

\title{
Palabras clave
}

Jurisprudencia del Tribunal de Justicia; Medidas cautelares; Orden público de la UE; Interés público de la UE; Efecto útil; Tutela judicial efectiva; Derecho de la competencia; Protección de los consumidores; Protección del interés del menor.

\section{THE NATIONAL JUDGE OF INTERIM MEASURES AND THE PROTECTION OF THE PUBLIC ORDER AND THE PUBLIC INTEREST OF THE EUROPEAN UNION}

\begin{abstract}
During the last few years the European Court of Justice has established a consistent case law strengthening the fundamental role of member States judges acting as EU ordinary judges, assigning them some powers in interim measures, when public interest of the EU or its public order is threatened.

It's quite a new phenomenon that increases the duty of diligence of the national judges in charge of interim measures, who must ensure the effectiveness of those provisions and legal principles at issue, as well as prevent infringements of such fundamental elements of EU legal order, which claim to be protected and applied in its entirety among all member States.

The whole of the European Court of Justice decisions which developed the afore mentioned regime of competence on interim measures for national judges, stands out for its dynamism, high technicality and because it tends to some didactics.

This jurisprudence highlights a common thread: the balance between effectiveness of EU law and the due discretion of the national judge who is compelled to ensure effective judicial protection.
\end{abstract}

\section{Key words}

ECJ case law; interim measures; public order of the EU; public interest of the EU; effective judicial protection; competition law; consumer's protection; child's interest protection. 


\section{LE JUGE NATIONAL DES MESURES PROVISOIRES ET LA PROTECTION DE L'ORDRE PUBLIC ET DE L'INTERET PUBLIC DE L'UNION EUROPEENNE}

\section{Résumé}

La Cour de justice de l'Union européenne a établi au cours de ces derniers ans une jurisprudence par laquelle renforce la fonction essentielle des organes juridictionnels des États membres comme les juges ordinaires du droit de l'Union, en leur attribuant certains pouvoirs pour adopter des mesures provisoires lorsque la protection de l'ordre public et de l'intérêt public de l'Union européenne est en jeu.

Il s'agit d'un phénomène nouveau qui renforce le devoir de diligence du juge national des mesures provisoires, car, outre l'obligation de garantir l'effet utile des dispositions et principes dont il s'agit, il a également l'obligation d'éviter que ces derniers ne soient transgressés, compte tenu qu’ils sont des éléments essentiels du système juridique de l'Union européenne et qu'ils doivent être intégralement protégés sur l'ensemble du territoire de ses États membres.

L'ensemble des décisions importantes de la Cour de justice qui articule le régime de cette attribution de pouvoir provisoire aux juges nationaux se caractérise par son dynamisme, sa haute précision technique et par sa tendance à être un certain composant didactique.

Cette doctrine a un dénominateur commun qui préserve l'équilibre entre la protection nécessaire de l'effet utile du Droit de l'Union et le respect à l'autonomie du juge national qui doit garantir l'exercice du droit à la protection judiciaire effective.

\section{Mots clés}

Jurisprudence de la Cour de justice; Mesures provisoires; Ordre public de l'UE; Intérêt public de l'UE; Effet utile; Protection judiciaire effective; Droit de la concurrence; Protection des consommateurs; Protection de l'intérêt du mineur. 


\section{SUMARIO}

I. INTRODUCCIÓN. II. FUNDAMENTO Y FINALIDAD DE LA TUTELA CAUTELAR DEL JUEZ NACIONAL DE LOS DERECHOS RECONOCIDOS EN EL ORDENAMIENTO DE LA UE. III. LA AUTONOMÍA DEL JUEZ NACIONAL DE MEDIDAS CAUTELARES A LA LUZ DE LA JURISPRUDENCIA DEL TRIBUNAL DE JUSTICIA. IV. EL ORDEN PÚBLICO Y EL INTERÉS PÚBLICO EN EL ORDENAMIENTO DE LA UE: 1. La delimitación de los elementos que configuran el orden público y su función en el ordenamiento de la UE; 2. La noción de interés público y su función en el ordenamiento de la $\mathrm{UE} ; 3$. La relación entre las disposiciones y principios de orden público y de interés público de la UE y los ordenamientos internos de los Estados miembros. V. EL JUEZ NACIONAL DE MEDIDAS CAUTELARES Y LA TUTELA DEL ORDEN PÚBLICO Y DEL INTERÉS PÚBLICO DE LA UE: 1. La tutela del orden público y el derecho de la competencia de la UE; 2 . La tutela del interés público y la protección de los consumidores en el derecho de la UE; 3 . La tutela del orden público y la cooperación judicial en el Espacio de Libertad, Seguridad y Justicia. VI. CONCLUSIONES.

\section{INTRODUCCIÓN}

Entre las relevantes aportaciones del Tribunal de Justicia (en adelante, «TJ») como garante de la aplicación del derecho de la Unión Europea destaca, por su singularidad, la iniciativa de atribuir la potestad de conceder la tutela cautelar de los derechos y libertades reconocidos en dicho ordenamiento a los órganos jurisdiccionales internos en el territorio de sus Estados miembros.

El ejercicio de esta prerrogativa excepcional por los jueces nacionales completa su labor de jueces ordinarios del derecho de la Unión y contribuye a apuntalar el sistema de garantías de los justiciables mediante el fortalecimiento del derecho a la tutela judicial efectiva.

Dado que se trata de una atribución competencial cuyo fundamento originario es la doctrina establecida por el TJ, tiene lugar de forma progresiva y un tanto asistemática, al hilo de la casuística que evidencia las necesidades que dan lugar a empoderamientos concretos de los jueces nacionales. Recien- 
temente, algunos instrumentos normativos de derecho derivado reconocen expresamente también dicha potestad a los órganos jurisdiccionales internos, sujeta al cumplimiento de diversos requisitos establecidos en los mismos. El TJ ha elaborado una relevante doctrina acerca de la aplicación y de la interpretación de los mismos.

Este estudio analiza la emergente configuración jurisprudencial de un régimen específico de salvaguardia de las disposiciones y principios del orden público y del interés público del derecho de la Unión Europea, mediante su tutela cautelar por los órganos jurisdiccionales de los Estados miembros.

Es un fenómeno novedoso por cuanto focaliza el deber de diligencia del juez nacional de medidas cautelares, ya que, junto con la obligación de garantizar la correcta aplicación de las citadas disposiciones y principios, tiene, también, la obligación de evitar que se violen los mismos en cuanto elementos fundamentales del sistema jurídico de la Unión que deben de ser protegidos íntegramente, con un nivel idéntico de eficacia en todos los Estados miembros.

Ciertamente, junto con la propia complejidad que supone intentar establecer una sistematización de las reglas de actuación que fija la doctrina del TJ para el juez nacional de medidas cautelares desde el reconocimiento de esta facultad en la jurisprudencia Factortame hasta nuestros días, se añade aquí la cuestión referente a los límites de la autonomía de la que dispone para discernir, según las circunstancias del caso, si la adopción de una medida cautelar es facultativa o imperativa a efectos de salvaguardar el efecto útil de las disposiciones y principios de orden público y del interés público, y la propia tutela judicial efectiva de los derechos en juego.

Consiguientemente, la elaboración del presente estudio se ha realizado sobre un análisis de conjunto, y lo más exhaustivo posible, del importante elenco jurisprudencial en esta materia, del que se desprende el contenido de los cuatro epígrafes centrales que lo desarrollan, y que sigue a su vez un discurso cronológico de conformidad con el cual se abordan inicialmente, en los epígrafes II y III, las sentencias en las que el TJ estableció los elementos esenciales (condiciones, requisitos, etc.), en suma, el «régimen general» conforme al cual puede ejercer sus facultades el juez nacional de medidas cautelares cuando tutela derechos y libertades reconocidos en el ordenamiento jurídico de la Unión Europea (en adelante, «UE»).

Una vez expuesto el prolijo régimen en cuestión haciendo un énfasis especial sobre sus efectos en la autonomía del ejercicio de la función del juez nacional de medidas cautelares, el epígrafe IV se dedica a identificar los rasgos específicos de las nociones de orden público y de interés público en el derecho de la UE, tal y como han sido establecidos en la jurisprudencia del TJ, subrayando la relevante dimensión axiológica que ésta les reconoce. 
Adquiere aquí peso específico propio la cuestión de la integración de las disposiciones y principios calificados por el Tribunal como de orden público y de interés público en los ordenamientos internos de los Estados miembros, ya que una aplicación adecuada de los mismos requerirá, según los casos, integrar lagunas jurídicas ante la falta de previsiones internas, o cercenar la discrecionalidad de los poderes públicos nacionales cuando la invocación de sus propias normas de orden público e interés público resulta incompatible o contraria a la aplicación de aquellos.

En el epígrafe $\mathrm{V}$ se expone el incremento de las atribuciones que, de forma singularizada, recibe el juez nacional de medidas cautelares a través de una jurisprudencia establecida por el TJ en los últimos años para garantizar la tutela de las disposiciones y principios que nos ocupan y que tienen que ver con su aplicación en el ámbito del derecho de la competencia de la UE, con la protección de los consumidores en dicho ordenamiento, y con la cooperación judicial en el Espacio de Libertad, Seguridad y Justicia.

En suma, aunque están vigentes diversos instrumentos normativos que prevén expresamente la atribución a los jueces nacionales de la competencia cautelar para tutelar derechos y libertades reconocidos en los mismos, un ejercicio cabal de esta potestad que sea plenamente conforme con la protección del efecto útil del derecho de la Unión y con el principio de la tutela judicial efectiva, deberá conformarse a los cánones establecidos en la jurisprudencia del TJ. Especialmente, en aquellas circunstancias en las que esté en juego la salvaguardia de disposiciones o principios del orden público y del interés público de la UE.

\section{FUNDAMENTO Y FINALIDAD DE LA TUTELA CAUTELAR DEL JUEZ NACIONAL DE LOS DERECHOS RECONOCIDOS EN EL ORDENAMIENTO DE LA UE}

La facultad de conceder una tutela jurídica provisional o cautelar de los derechos reconocidos en el ordenamiento jurídico de la UE por parte de los órganos jurisdiccionales nacionales está fundada en dicho ordenamiento tal y como lo establece una relevante jurisprudencia del $\mathrm{TJ}^{2}$.

2 Véanse, entre otras, las sentencias del TJ, Factortame, C-213/89, EU:C:1990:257, apdos. 21 y 22, y Zuckerfabrik, as. ac. C-143/88 y C-92/89, EU:C:1991:65, apdos. 19-21. Véanse igualmente, las conclusiones del Abogado General Tesauro en el asunto Factortame, EU:C:1990:257, punto 29; las conclusiones del Abogado General Lenz en el asunto Zuckerfabrik, EU:C:1996:65, punto 88, y, especialmente, las conclusio- 
Se trata, no obstante, de un empoderamiento que no es atribuido expresamente por ninguna disposición de los Tratados ni del derecho derivado, a diferencia de las que atribuyen al TJ y al Tribunal General (en adelante «TG») la competencia de ordenar la suspensión de la ejecución de actos impugnados ante su jurisdicción, o de ordenar las medidas provisionales que sean necesarias en determinados procedimientos ${ }^{3}$.

Como es sabido, su reconocimiento y desarrollo tiene lugar mediante un "revolucionario» acervo jurisprudencial del TJ que consolida la función de los jueces internos como jueces ordinarios de derecho de la Unión ${ }^{4}$. A la postre, la doctrina dictada por el TJ en coherencia con lo

nes del Abogado General Elmer en el asunto Atlanta, C-465/93, EU:C:1996:452, puntos 30 y 31 .

Como subraya García de Enterría al analizar la citada jurisprudencia en los asuntos Factortame y Zuckerfabrik, el TJ establece una regla fundamental en el orden de los principios del ordenamiento supranacional que habilita a los jueces nacionales para suspender a título cautelar tanto las normas internas del máximo rango, como la aplicación del propio derecho de la Unión, en Eduardo GARCÍA DE ENTERRÍA, La batalla por las medidas cautelares: Derecho Comunitario Europeo y Proceso Contencioso-Administrativo Español, $3^{\text {a }}$ ed., Thomson-Civitas, Cizur Menor (Navarra), 2006, p. 137.

Bien es cierto que, tanto la denominación de la tutela judicial en cuestión como las medidas que se adoptan para su implementación se inspiran en fórmulas extraídas de algunas tradiciones constitucionales de los Estados miembros de la Unión. Véase, en este sentido, Susana DE LA SIERRA, «Provisional Court Protection in Administrative Disputes in Europe: The Constitutional Status of Interim Measures Deriving from the Right to Effective Court Protection. A comparative Approach", European Law Journal, vol. 10, núm. 1, 2004, pp. 42-60, 44.

3 Arts. 278 y 279 del Tratado de Funcionamiento de la UE (TFUE), respectivamente, arts.160-166 del Capítulo Décimo del Título Cuarto del Reglamento de Procedimiento del TJ (DO L 265, de 29 de diciembre de 2012, p. 1), y arts.156-160 de la Sección 2 del Capítulo decimosexto del Título Tercero del Reglamento de Procedimiento del TG (DO L 105, de 23 de abril de 2015, p. 1). Igualmente, Normas 264268 del Apdo. B del Título VIII de las Normas prácticas de desarrollo del Reglamento de Procedimiento del TG (DO L 152, de 18 de junio de 2015, p. 1). Sobre esta cuestión, véase Marc JAEGER, «Le référé devant le président du Tribunal de l'Union européenne depuis septembre 2007», Journal de droit européen, núm. 131, 7/2010, pp. 197-213.

4 Gil Carlos RODRÍGUEZ IGLESIAS, «La tutela judicial cautelar en el derecho comunitario", en Gil Carlos RODRÍGUEZ IGLESIAS y Diego J. LIÑÁN NOGUERAS (dirs.), El derecho comunitario europeo y su aplicación judicial, Civitas, Madrid, 1993, pp. 633-652, 634. 
dispuesto en el párrafo primero del art. 19 del Tratado de la Unión Europea (en adelante, «TUE») , resulta un acicate esencial para que los Estados miembros cumplan con lo previsto en el párrafo segundo del propio art. 19 en lo concerniente al deber de establecer las vías de recurso necesarias que garanticen la tutela judicial efectiva en los ámbitos cubiertos por el ordenamiento europeo ${ }^{6}$.

Consiguientemente, y tal y como ha reiterado el TJ en diversas sentencias, la tutela cautelar en cuestión debe perseguir una pluralidad de objetivos, dos de cuyos principales exponentes son, salvaguardar el «efecto útil» del derecho de la Unión y satisfacer el derecho de los justiciables que han manifestado un interés en la demanda sobre el procedimiento de fondo ${ }^{7}$.

La adopción por los jueces nacionales de las medidas cautelares pertinentes resulta especialmente necesaria en los casos donde esté en juego la primacía de aplicación de las disposiciones del derecho de la Unión que atribuyen directamente derechos y libertades a los particulares ${ }^{8}$. Esta circunstancia les obliga a actuar en calidad de jueces de la Unión' ${ }^{9}$, motivo por el cual el TJ ha precisado que las prerrogativas otorgadas a los órganos judiciales internos para su tutela cautelar no pueden, sin embargo, atribuirse a los órganos administrativos internos dado que estos no gozan de la presunción de independencia e imparcialidad de aquellos ${ }^{10}$.

Como corolario de la labor pretoriana que nos ocupa, la consagración del derecho a una tutela judicial efectiva en el párrafo primero del art. 47 de la Carta de los Derechos Fundamentales de la Unión Europea ${ }^{11}$ (en adelante, «CDFUE»), garantiza la protección más amplia posible que los jueces inter-

5 Que dice, «inter alia» que "garantizará el respeto del Derecho en la interpretación y aplicación de los Tratados».

6 Véase el auto del TJ, Storch, C-64/14P, EU:C:2015:300, apdo. 48.

7 Así, por ejemplo, sentencias Factortame, cit. EU:C:1990:257, apdos. 18-21; Zuckerfabrik, cit. EU:C:1995:65, apdos. 16-21; auto del presidente del TJ, Akzo Nobel, C-7/04 P(R), EU:C:2004:566, apdo. 36; etc. Véanse, igualmente, las consideraciones del Abogado General Tesauro en los puntos 11, 18 y 19 de sus conclusiones en el asunto Factortame, cit. EU:C:1990:257.

8 Sentencia Factortame, cit. apdos. 17-20.

9 Véanse las conclusiones del Abogado General Lenz en el asunto Zuckerfabrik, cit. EU:C:1991:65, puntos 11 y 12. Igualmente, las conclusiones del Abogado General Tesauro en el asunto Factortame, EU:C:1990:257, puntos 12-15.

10 Sentencia del TJ Fratelli Martini, as. ac. C-455/03, C-11/04, C-194/04 y C-453/03, EU:C:2005:741, apdos. 108 y 109.

11 DO C 303, de 14 de diciembre de 2007, p. 1 y DO C 83, de 30 de marzo de 2010, p. 389. 
nos puedan otorgar cuando se aplica el derecho de la Unión ${ }^{12}$, incluida la facultad de conceder medidas cautelares si fuera necesario ${ }^{13}$.

Ello supone en suma cumplir con el principio de efectividad del derecho de la Unión ${ }^{14}$ que, aunque no establece un deber general de que los órganos jurisdiccionales nacionales tutelen en cualquier circunstancia los derechos reconocidos en dicho ordenamiento ${ }^{15}$, sí que implica la garantía de que las partes dispongan de la posibilidad de beneficiarse de sus disposiciones ${ }^{16}$.

La jurisprudencia del TJ confirma la radicalidad del citado principio al atribuirle al juez nacional la facultad de adoptar medidas cautelares que garanticen la plena eficacia de su decisión final evitando el menoscabo del efecto útil del derecho de la Unión, aunque ello no sea conforme con el régimen procesal interno de un Estado miembro ${ }^{17}$.

Este empoderamiento resulta, en fin, plenamente conforme con la noción de «efectividad de la tutela» que, como ya se reseñó anteriormente fue proclamada por el propio TJ sin que existiera un reconocimiento expreso en

12 Según establece el párrafo segundo de la explicación al citado art. 47 de la CDFUE.

13 Ciertamente, las modalidades de la tutela cautelar del derecho de la Unión deberán atenerse al derecho interno de los Estados miembros, aunque no deberán ser menos favorables que las relativas a las de la tutela de los derechos fundados en normas nacionales; véanse, en este sentido, las conclusiones del Abogado General Tesauro en el asunto Factortame, cit., puntos 14 y 30. Queda en todo caso excluida la posibilidad de que los jueces nacionales puedan abusar de la facultad de acordar medidas cautelares para dictar disposiciones normativas en lugar de las Instituciones competentes de la Unión; véanse las conclusiones del Abogado General Elmer en el asunto Atlanta cit., EU:C:1996:452, punto 21.

14 Véase, por ejemplo, la sentencia del TJ Courage, C-453/99, EU:C:2001:465, apdos. 25-27 y 29. Como botones de muestra de la aplicación del citado principio en el ámbito que nos ocupa, véanse los asuntos analizados por Fernando CASTILLO DE LA TORRE: «Interim measures in Community Courts: Recent Trends», Common Market Law Review, vol. 44, núm. 2, 2007, pp. 273-353.

15 Véase, por ejemplo, la sentencia del TJ Van Schijndel, as. ac. C-430/93 y C-431/93, EU:C:1995:441, apdos. 20-22.

16 Véase, por ejemplo, las sentencias delTJ Baczó y Viznyiczai, C-567/13, EU:C:2015:88, apdo. 59; Océano, C-240/95 a C-244/98, EU:C:2000:346, apdo. 26; Cofidis, C-473/00, EU:C:2002:75, apdos. 32-33; y Peterbroek, C-312/93, EU:C:1995:437, apdos. 13-14 y 21.

17 Véase la sentencia del TJ Aziz, C-415/11, EU:C:2013:164, apdos. 52 y 59-64. Igualmente, las conclusiones del Abogado General Jacobs presentadas en el asunto Unión de Pequeños Agricultores, cit. C-500/00 P, EU:C:2002:462, punto 38. 
los Tratados, ni en el derecho derivado ${ }^{18}$, y que actualmente consagra el citado art. 47 de la CDFUE ${ }^{19}$.

\section{LA AUTONOMÍA DEL JUEZ NACIONAL DE MEDIDAS CAUTELARES A LA LUZ DE LA JURISPRUDENCIA DEL TRIBUNAL DE JUSTICIA}

En una aproximación inicial al tema que nos ocupa, según la jurisprudencia Factortame, podría interpretarse que el TJ atribuye a los órganos jurisdiccionales internos un amplio margen, casi una total discrecionalidad para decidir la concesión de medidas cautelares en los litigios en que se invoquen derechos con base en el derecho de la Unión ${ }^{20}$.

Ciertamente, $y$, aunque existían precedentes en los que, tras plantear una cuestión prejudicial, algunos órganos jurisdiccionales internos habían ordenado por su propia iniciativa medidas provisionales que inaplicaban la normati-

18 Sentencia Zuckerfabrik, cit. apdos. 17-21. Sentencia Factortame, cit. apdos. 20-22. Igualmente, conclusiones del Abogado General Tesauro en el Asunto Factortame, cit. puntos 18 y 19.

Véanse, no obstante, las observaciones críticas al razonamiento del TJ sobre el alcance del principio de la tutela judicial efectiva en el asunto Factortame, realizadas por Denys SIMON y Ami BARAV, «Le droit communautaire et la suspension provisoire des mesures nationales. Les enjeux de l'affaire Factortame», Revue du marché commun, núm. 340, 1990, pags. 591-597, 596.

19 Sin embargo, como ha precisado el TJ, la finalidad del citado art. 47 CDFUE no es la de modificar el sistema de control jurisdiccional previsto en los Tratados, especialmente en lo relativo a la admisión de recursos directos ante el Tribunal; véase la sentencia del TJ, Inuit, C-583/11P, EU:C:2013:625, apdos. 97 y 98. Por otra parte, corresponde a las jurisdicciones internas interpretar las condiciones de aplicación de esta disposición de la CDFUE para garantizar que se protegen adecuadamente los intereses de los justiciables; véase el Auto del TJ Forgital, C-84/14P, EU:C:2015:517, apdo. 66. Asimismo, el TG invoca el art. 47 de la CDFUE en diversas decisiones sobre medidas provisionales; por ejemplo, Auto del presidente del TG de 29 de noviembre de 2012, Alstom, T-164/12R EU:T:2012:637, apdo. 49; Auto del presidente del TG de 4 de diciembre de 2014, Vambreda Risk, T-199/14R, EU:T:2014:1024, apdo. 19.

20 Sentencia Factortame, cit., apdo. 21. Véase, en este sentido, Sophie BOYRON y Neville BROWN, «L'affaire Factortame, droit communautaire contre droit public anglais», Revue française de droit administratif, vol. 10, núm. 1, 1994, pp. 70-79; igualmente, Manuela MUSCARDINI, "Potere cautelare dei giudici nazionali in materia disciplinate dal diritto comunitario", Rivista italiana di diritto pubblico comunitario, vol. 1, núm. 4, 1991, pp. 1042-1064. 
va nacional presuntamente incompatible con el Derecho de la Unión ${ }^{21}$, el TJ no abordó directamente este transcendental problema hasta que sentencia el citado asunto Factortame.

Como es sabido, el TJ respondió a la cuestión principal remitida por la House of Lords británica, «si el juez nacional que conoce de un litigio referente al derecho comunitario y que considera que el único obstáculo que se opone a que él pueda ordenar medidas provisionales es una norma del derecho nacional ha de excluir la aplicación de esta norma ${ }^{22} »$, estableciendo claramente que el órgano jurisdiccional nacional «debe excluir la aplicación de dicha norma $^{23}$.

La concisión de la respuesta dejó sin atar, empero, ciertos flecos que atañen al margen de discrecionalidad del juez nacional para dilucidar la oportunidad de la concesión de medidas cautelares y los criterios con los que fundamentarla, extremos ambos que si habían sido abordados exhaustivamente por el Abogado General Tesauro en sus conclusiones a este asunto ${ }^{24}$.

En síntesis, se pretendía determinar si el derecho de la Unión obliga al juez nacional a conceder la tutela cautelar, o si le faculta para ello, dependiendo a su vez de esta respuesta si dicho órgano dispone o no de libertad para elegir los criterios de concesión de la misma.

Esta incertidumbre fue pronto despejada por el TJ en el asunto Zuckerfabrik, donde establece el marco básico que limita mediante criterios supranacionales la autonomía del juez nacional de medidas cautelares.

La cuestión central planteada por el Finanzgericht de Hamburgo (Alemania) se refiere a la competencia de los órganos jurisdiccionales nacionales en el marco de un procedimiento sobre medidas provisionales, para suspender la ejecución de un acto administrativo nacional basado en un reglamento comunitario ${ }^{25}$. Se trataba de una situación novedosa en la que el juez nacional, sin pretender decidir acerca de la validez del acto comunitario, se enfrenta a la posibilidad de diferir la aplicación del acto interno de ejecución con el consiguiente perjuicio a la plena eficacia de aquél.

La respuesta del TJ consta de dos partes diferentes. La primera parte atribuye, aparentemente, un amplio margen de autonomía al juez nacional de medidas cautelares al interpretar que la disposición controvertida, el pá-

21 Véase la relación de asuntos citados en las conclusiones del Abogado General Tesauro en el asunto Factortame, cit., nota núm. 6, punto 16.

22 Sentencia Factortame, cit., apdo. 17.

23 Ibid., apdo. 23.

24 Conclusiones del Abogado General Tesauro en el asunto Factortame, cit., punto 33.

25 Sentencia Zuckerfabrik, cit., apdos. 1 y 14. 
rrafo segundo del art. 189 del Tratado CEE, no excluye la facultad de dicho órgano de ordenar la suspensión de la ejecución de acto interno fundado en un reglamento comunitario ${ }^{26}$. Pero, dado que la decisión que adopte en este caso el juez nacional de medidas cautelares se sustenta en un empoderamiento supranacional y afecta a la aplicación de actos de derecho de la Unión, su autonomía queda sujeta por el deber de respetar un conjunto de condiciones establecidas expresamente por el TJ en la misma sentencia. Consiguientemente, la suspensión de la aplicación del acto interno de ejecución del reglamento controvertido está supeditada a plantear inmediatamente una cuestión prejudicial para que el TJ se pronuncie sobre su validez, debiendo determinar además el órgano jurisdiccional interno los motivos de la presunta invalidez ${ }^{27}$.

A mayor abundamiento, la adopción de la medida cautelar de suspensión sólo puede adoptarse si las circunstancias de hecho y de derecho alegadas por el demandante inducen al juez nacional al convencimiento de que existen serias dudas sobre la validez del reglamento controvertido ${ }^{28}$, y deberá atenerse a estrictos requisitos de concesión: que se cumplan los criterios de adopción de medidas provisionales en los procedimientos seguidos ante el TJ, especialmente la urgencia, y que se tenga en cuenta el interés de la Unión, lo que exige entre otras cosas la imposición al demandante de suficientes garantías, como la prestación de una fianza o la constitución de un depósito judicial ${ }^{29}$.

La aplicación de límites a la autonomía de los órganos jurisdiccionales internos es confirmada y desarrollada por la sentencia del TJ en el asunto $A t$ lanta, que dilucidó la cuestión de si estos disponen de la facultad de adoptar medidas cautelares que supongan la inaplicación de un reglamento hasta que aquél se pronuncie sobre su validez en el procedimiento prejudicial que se le ha planteado ${ }^{30}$.

26 Ibid., apdos. 18-21.

27 Ibid., apdo. 24.

28 Ibid., apdo. 23.

29 Ibid., apdos. 25-33. Según RODRÍGUEZ IGLESIAS, el enunciado de las condiciones sustanciales necesarias para la adopción de medidas provisionales por el TJ puede ocultar el criterio esencial, que es asegurar la eficacia de la resolución que finalmente se adopte sobre el fondo del litigio, lo cual exige tomar en consideración y valorar todos los intereses en juego; op. cit., pp. 640-642.

30 Sentencia Atlanta, cit., apdo. 1. Sobre el alcance jurídico de esta sentencia véanse, entre otros, Gerhard BEBR, "Cases C-465 and 466/93, Atlanta” Commentaire sous l'arrêt Atlanta", Common Market Law Review, vol. 33, núm. 4, 1996, pp. 795-809; Leonardo LIMBERTI, "Principio della concedere provedimenti "positivi" ", Rivista italiana di diritto pubblico comunitario, 1996, núm. 5, pp. 991-1002; Rostane MEHDI, «Le droit communautaire et les pouvoirs du juge national de l'urgence», Revue 
La novedad de este asunto es que el juez nacional no pregunta al TJ sobre la suspensión de la ejecución de un acto interno adoptado con base en un reglamento comunitario, sino sobre la concesión de una medida positiva que hace provisionalmente inaplicable ese reglamento ${ }^{31}$.

La respuesta del TJ se limitó inicialmente a establecer que una interpretación del Tratado «no excluye» esta facultad de los órganos jurisdiccionales nacionales ${ }^{32}$, advirtiendo, no obstante, de los límites que condicionan dicha facultad al hilo de la respuesta a una segunda cuestión del órgano jurisdiccional remitente sobre los requisitos que deben reunirse para adoptar tales medidas cautelares; así, tras confirmar que deben cumplirse todos los establecidos en la sentencia Zuckerfabrik ${ }^{33}$, precisa detalladamente su aplicación, lo que supone un severo constreñimiento de la autonomía del juez nacional de medidas cautelares ${ }^{34}$.

En definitiva, las medidas provisionales no deben crear situaciones jurídicas más beneficiosas para el interesado que las que pudieran derivarse de una sentencia definitiva favorable a sus pretensiones, ni deben constituir un medio sustitutivo para que las jurisdicciones internas dicten disposiciones normativas en lugar de las instituciones competentes de la Unión. Por otra parte, dichas jurisdicciones deberán atenerse a la jurisprudencia del TJ sobre la aplicación de los arts. 278 y 279 del TFUE, y ser diligentes para anular las medidas provisionales frente al acto jurídico de la Unión controvertido ${ }^{35}$. Se trata de imponer el modelo supranacional seguido por el TJ y el TG de forma que se colme la laguna existente por la falta de un régimen jurídico uniforme en la materia ${ }^{36}$.

De la doctrina elaborada por el TJ se desprende claramente que el juez nacional de medidas cautelares puede enfrentarse a dos tipos de situaciones

trimestrielle de droit européen, núm. 1, 1996, pp. 77-100; José Manuel SOBRINO HEREDIA, «La incidencia del derecho Comunitario sobre la facultad de los órganos jurisdiccionales nacionales de adoptar medidas cautelares de contenido positivo», Revista de Instituciones Europeas, vol. 23, núm. 3, 1996, pp. 779-797.

31 Sentencia Atlanta, cit., apdos. 19 y 26.

32 Ibid., apdos. 27-28 y 30.

33 Ibid., apdos. 32-33.

34 Ibid., apdos. 34-50.

35 Conclusiones del Abogado General Elmer en el asunto Atlanta, cit., puntos 11, 21, 27-28.

36 Véase Sergio ARIEL APTER, «Interim Measures in EC Law: Towards a Complete and Autonomous System of Provisional Judicial Protection before National Courts?», Electronic Journal of Comparative Law, vol. 7, núm. 2, 2003, disponible en: http:// www.ejcl.org/72/art72-1.html. 
en las que el ejercicio de su autonomía difiere sustancialmente. Por una parte, frente a actos internos adoptados en aplicación del derecho de la Unión y cuya validez se impugna, circunstancia en la que disfruta de amplias prerrogativas para evaluar y decidir lo que sea pertinente en cada caso. Y, por otra parte, frente a actos internos adoptados en ejecución de normas de la Unión, generalmente reglamentos, presuntamente viciadas de nulidad, donde su autonomía está limitada por un conjunto de obligaciones y de reglas de actuación establecidas a nivel supranacional.

Al hilo de esta observación procede recordar que, según estableció el Tribunal en el asunto Antonissen, si la adopción por un órgano jurisdiccional nacional de una medida se refiere al anticipo cautelar del pago de las deudas de la Administración generadas por actos de mala administración, esta sólo podrá acordarse de manera restrictiva y siempre que el fumus boni iuris sea particularmente sólido y la urgencia incontestable ${ }^{37}$, ponderando además la posibilidad de acompañarla de otras condiciones que sean necesarias según el juez, incluyendo cualquier medio que reduzca su impacto ${ }^{38}$.

No obstante, el Tribunal reconoció en el citado asunto Antonissen la amplia facultad de apreciación de que disponen los jueces nacionales para verificar si, atendiendo a las particularidades de cada caso, se dan los requisitos necesarios para conceder las medidas solicitadas ${ }^{39}$; una jurisprudencia posterior corrobora también su capacidad para establecer el orden con el que examinarán la existencia de dichos requisitos ${ }^{40}$.

Los órganos jurisdiccionales internos deberán tomar en cuenta, en suma, el amplio acervo jurisprudencial del TJ y del TG en este ámbito. Así, por ejemplo, no es pertinente adoptar estas medidas cuando la situación irregular deriva de una interpretación inadecuada de la normativa europea por las

37 Auto del presidente del TJ en el Antonissen, C-393/96 P (R), EU:C:1997:42, apdo. 41. Además, tal y como ha reiterado la jurisprudencia del TJ, se trata de requisitos que son acumulativos, de manera que las medidas provisionales deben ser denegadas cuando no se dé alguno de ellos, auto del presidente del TJ en el asunto Akzo, EU:C:2004:566, apdo. 28.

38 Auto del presidente del TJ en el asunto Antonissen cit., EU:C:1997:42, apdo. 42. Un análisis del impacto de este asunto en José Luis DA CRUZ VILAÇA, «La procédure en référé comme instrument de protection jurisdictionnelle des particuliers en droit communautaire», en Scritti in onore di Giuseppe Federico Mancini, Giuffré, Milano, 1998, vol. II, pp. 257-306. Véanse las sentencias del TJ Van Uden, C-391/95, EU:C:1998:543, apdo. 47, y Mietz, C-99/96, EU:C:1999:202, apdo. 42.

39 Auto del presidente del TJ Antonissen, cit., apdos. 28-34.

40 Auto del presidente del TJ Vischim, C-459/06 P (R), EU:C:2007:209, apdo. 25. 
autoridades nacionales tales como la elaboración de disposiciones confusas o insuficientes en la transposición de una directiva, circunstancia habitual en materia de protección del medioambiente, pero que, en opinión del TJ, a duras penas justifica la existencia de urgencia ${ }^{41}$.

Precisamente, la determinación del carácter urgente de una demanda de medidas provisionales debe ser objeto de una minuciosa evaluación por parte del órgano judicial nacional si atendemos a lo establecido en la jurisprudencia relevante del TJ y del TG. Si se trata de adoptar medidas cuyo objeto reviste consecuencias excepcionales ${ }^{42}$ o de duración muy limitada ${ }^{43}$, el demandante deberá probar fehacientemente su carácter urgente ${ }^{44}$.

Se exige también la existencia de un nexo directo entre el acto impugnado y el daño sufrido por el demandante, quién deberá probar su actuación diligente al respecto ${ }^{45}$, y una afectación directa, individual y singularizada a sus intereses jurídicos ${ }^{46}$.

41 Véase el análisis de la jurisprudencia relevante en Martin HEDEMANN-ROBINSON, «Enforcement of EU Environmental Law and the Role of Interim Relief Measures», European Energy and Environmental Law Review, vol. 19, núm. 5, 2010, pp. 204-229, especialmente 213-216. Este autor critica la posición del TJ y advierte de su posible incompatibilidad con la preservación de bienes jurídicos superiores como la salud de las personas o de otros objetivos consagrados en la normativa europea tales como la consecución de altos estándares de protección medioambiental, el bienestar animal y el equilibrio ecológico, pp. 228-229.

42 Auto del presidente del Tribunal de Primera Instancia (TP1) de 19 de diciembre de 2001 Gibraltar/Comisión, T-195/01 R y T-207/01 R, EU:T:2001:291, apdo. 115.

43 Auto del presidente del TJ Emesa Sugar, C-363/98 P (R), EU:C:1998:628, apdos. 55-56.

44 Ello ocurre, por ejemplo, cuando el interesado se esfuerza a tiempo y con seriedad en obtener un aval bancario para cubrir la multa que le ha sido impuesta, pero se le deniega sistemáticamente su concesión por todos los establecimientos financieros a los que se lo solicita como consecuencia de la grave situación económica en la que se encuentra, resultando por ello necesario que se determine una reducción, incluso sustancial, de la multa en cuestión; véase el auto del presidente del TG de 15 de diciembre de 2015, CCPL-Consorzio Cooperative di Produzione e Lavoro SC, T-522/15R, EU:T:2015:1012, apdos. 60-64 y 78.

45 Auto del presidente del TJ Marcuccio, C-399/02 P (R), EU:C:2003:90, apdo. 26.

46 Véase el auto del TJ Storch, C-64/14P, EU:C:2015:300, apdos. 29-44. Los particulares no pueden alegar perjuicios causados a terceros o al interés general salvo en supuestos en los que deban considerarse los intereses concurrentes. Véanse, en este sentido, el auto del presidente del TP1 de 5 de julio de 2005, Rodenbröker, T-117/05 R, EU:T:2005:273, apdo. 75, y la jurisprudencia que se cita. 
En los casos de paridad entre los intereses particulares deberán tutelarse preferentemente los que conciernan más directamente al interés general ${ }^{47}, \mathrm{y}$ en cualquier circunstancia habrá de preservarse la protección de la salud pública frente a los intereses económicos que puedan estar en juego ${ }^{48}$.

Los perjuicios económicos se ponderan a su vez de forma diferente tratándose de personas físicas o de personas jurídicas, ya que mientras que para aquellas resultará determinante la simple prueba documental de su capacidad para disponer o no de los recursos mínimos vitales de supervivencia ${ }^{49}$, las personas jurídicas, especialmente las empresas deben informar verazmente de su situación contable y de sus actividades a efectos de calibrar el impacto para su viabilidad de una posible denegación de las medidas solicitadas ${ }^{50}$.

En cuanto a la naturaleza del daño, deberán descartarse, salvo que concurran en el caso circunstancias extraordinarias, los daños meramente económicos, dado que es posible su reparación ${ }^{51}$, así como los de carácter incierto ${ }^{52}$ o hipotético ${ }^{53}$. Similarmente, no se consideran capaces de generar un daño irreparable las violaciones a los derechos de propiedad industrial o intelectual que alegue el demandante con carácter exclusivo ${ }^{54}$.

Ello no obstante, el órgano jurisdiccional nacional dispone de cierto grado de libertad en el ámbito del procedimiento cautelar que nos ocupa en lo concerniente, por ejemplo, a la solicitud de pruebas, el establecimiento del plazo para que las partes presenten sus observaciones, para conceder unas me-

47 Auto del presidente del TP1 de 15 de noviembre de 2007, Donnici, T-215/07 R, EU:T:2007:344, apdos. 106-113, especialmente los apdos. 109-110.

48 Auto del Vicepresidente del TJ Comisión / Alemania, C-426/13 P (R), EU:C:2013: 848, apdos. 71-78, especialmente apdo. 77. Auto del presidente del TP1 de 11 de abril de 2003, Solvay, T-392/02 R, EU:T:2003:116, apdo. 122.

49 Auto del presidente del TG de 27 de abril de 2010, Parlamento Europeo/U, T-103/10 P (R), EU:T:2003:164, apdos. 48-52 y 56.

50 Auto del presidente del TJ Almamet, C-.373/10 P (R), EU:C:2010:792, apdo. 24. Similarmente, auto del presidente del TJ Comisión /Bruno Farmaceutici, C-474/00 P (R), EU:C:2001:219, apdos. 106-107, y, auto del presidente del TG de 9 de junio de 2010, Colt, T-79/10 R, EU:T:2010:228, apdo. 37.

51 Auto del presidente del TJ en el asunto Comisión/Cambridge Healthcare Supplies, C-471/00 P (R), EU:C:2001:218, apdo. 113.

52 Auto del presidente del TP1 de 26 de julio de 2006, Olympic Airlines, T-416/05 R, EU:T:2006:173, apdos. 52-60, especialmente el apdo. 52 y jurisprudencia que se cita.

53 Auto del presidente del TP1 de 3 de febrero de 2004, Enviro Tech Europe, T-422/03R, Rec., EU:T:2004: 30, apdo. 65 y jurisprudencia que se cita.

54 Auto del presidente del TP1 de 22 de diciembre de 2004, Microsoft, T-201/04 R, Rec., EU:T:2004:372, apdos. 250-251. 
didas distintas de las solicitadas, para dirigir órdenes conminatorias a terceros ajenos al procedimiento en circunstancias excepcionales para el demandante ${ }^{55}$, para decidir la modificación o la revocación de oficio del auto de concesión de la medida de que se trate; etc. ${ }^{56}$

Como veremos a continuación, el juez nacional de medidas cautelares deberá aquilatar los márgenes de autonomía de los que disfruta a otros requisitos y condicionamientos específicos que se derivan de la doctrina establecida por el $\mathrm{TJ}^{57}$, y por el TG, para garantizar la tutela del orden público y del interés público en el ámbito normativo supranacional.

\section{EL ORDEN PÚBLICO Y EL INTERÉS PÚBLICO EN EL ORDENAMIENTO DE LA UE}

Con frecuencia, el orden público y el interés público tienden a utilizarse como nociones similares en la práctica administrativa y en los entornos normativos de los Estados europeos. Sin embargo, y tal y como se desprende de la doctrina del TJ, en el ordenamiento jurídico de la UE, ambas nociones se tratan generalmente como categorías jurídicas diferenciadas, circunstancia que tiene unas consecuencias relevantes a los efectos del presente estudio ${ }^{58}$.

\section{LA DELIMITACIÓN DE LOS ELEMENTOS QUE CONFIGURAN EL ORDEN PÚBLICO Y SU FUNCIÓN EN EL ORDENAMIENTO DE LA UE}

En el estado actual del derecho de la Unión no es posible formular concisamente la noción de orden público, si bien el TJ ha declarado que participan de dicha naturaleza todas aquellas disposiciones y principios que constituyen sus fundamentos jurídicos ${ }^{59}$.

55 Auto del presidente del TP1 de 18 de marzo de 2008, Aerlingus, T-411/07 R, Rec. EU:T:2008:80, apdos. 55-58.

56 Véase, Antonio CREUS CARRERAS, «Las medidas cautelares en el escenario del Derecho de la Unión Europea», en Carlos J. MOREIRO GONZÁLEZ (dir.), Procedimientos Administrativos y Judiciales de la Unión Europea, Difusión Jurídica, Economist and Jurist, Madrid, 2012, pp. 535-580, p. 577.

57 Auto del presidente del TJ en el asunto Tillack, C-521/04 P (R), EU:C:2005:240, apdo. 38.

58 Véase, Alexander J. BELHALÁVEK, «Public Policy and Public Interest in International Law and EU Law», Czech Yearbook of International Law, vol. 3, 2012, pp. 117 147, especialmente 118-120.

59 Véase la sentencia del TJ Kadi, C-415/05P, EU:C:2008:461, apdo. 304. 
La calificación como normas de orden público se ha limitado, coherentemente, a las que se consideran esenciales en el marco jurídico supranacional, como por ejemplo los derechos fundamentale ${ }^{60}$ o ciertas disposiciones de los Tratados y del derecho derivado que cumplen misiones indispensables confiadas a la Unión y en especial para el funcionamiento del mercado interior ${ }^{61}$.

$\mathrm{Al}$ carecer de unos criterios estandarizados mediante los cuales pueda determinarse con precisión el carácter esencial de una disposición o de un principio del ordenamiento de la Unión, el concepto de orden público se configura, gradualmente, sobre la base de una casuística muy singular ${ }^{62}$.

Se trata, empero, de una noción propia del sistema jurídico de la $\mathrm{UE}^{63}$ que debe diferenciarse de las nociones de orden público europeo ${ }^{64} \mathrm{y}$ de orden público de los ordenamientos internos de los Estados miembros ${ }^{65}$, indepen-

60 Véanse las sentencias del TJ Trade Agency, C-619/10, /EU:C:2012:531, apdo. 52, y Krombach, C-7/98, EU:C:2000:164, apdos. 38 y 39.

61 Así lo determinó expresamente con relación al art. 101 del TFUE, y, con relación a la Directiva 93/13/CEE del Consejo, de 5 de abril de 1993, sobre cláusulas abusivas en los contratos celebrados con consumidores (DO L 95, p. 29), en las sentencias del TJ Mostaza Claro, C-168/05, EU:C:2006:675, apdo. 37, y Eco Swiss, C-126/97, EU:C:1999:269, apdo. 36. Generalmente una disposición del derecho derivado será considerada de orden público en la medida en la que especifique valores o principios consagrados en los Tratados o en la CDFUE.

62 Véase Christoph LIEBSCHER, «European Public Policy. A Black Box?», Journal of International Arbitration, vol. 17 (3), 2000, pp. 73-88, especialmente 80-81.

63 Véase Georges KARYDIS, «L'ordre public dans l'ordre juridique communautaire: un concept à contenu variable», Revue trimiestrielle de droit européen, vol. 38, núm. 1, 2002, pp. 1-26, especialmente 12-14. Igualmente, Marc FALLON, «Les conflicts de lois et de juridictions dans un espace économique intégré l'expérience de la communautè europeenne», Collected courses of the Hague Academy of International Law, Nijhoff, Leiden, vol. 253, 1995, pp. 9-282, especialmente 255.

64 Generalmente, se define como tal al conjunto de los valores comunes a las tradiciones jurídicas y constitucionales de los Estados europeos, cuya expresión más reseñable es el Convenio Europeo para la Protección de los Derechos Humanos y de las Libertades Fundamentales firmado en Roma el 4 de noviembre de 1950, en vigor desde el 3 de septiembre de 1953. Entre la numerosa literatura que ha abordado esta cuestión, véase el estudio de Roel DE LANGE, "The European Public Order, Constitutional Principiples and Fundamental Rights», Erasmus Law Review, vol. 1, núm. 1, 2007, pp. 3-24.

65 Sobre las relaciones entre el orden público de la UE y el orden público de sus Estados miembros, véase, entre otros, la parte IV, capítulo 12 de la monografía de Tim CORTHAUT, EU ordre public, Kluwer Law International, Alphen aan den Rijn, 2012. Igualmente, Ornella FERACI, «Il raporto tra ordine pubblico dell'Unione europea e 
dientemente del hecho de que todas ellas compartan algunos rasgos comunes tales como su adecuación a una escala de valores establecida en un momento concreto, su carácter abierto ${ }^{66}$ o la persecución de objetivos idénticos o similares al evitar la violación manifiesta de normas o principios esenciales o de derechos reconocidos en un ordenamiento jurídico determinado ${ }^{67}$.

En este sentido, y tal y como establece una reiterada jurisprudencia del $\mathrm{TJ}$, aunque la coexistencia entre dichas nociones supone respetar la libertad de los Estados miembros para determinar conforme a sus concepciones nacionales las exigencias de orden público, existen límites definidos a nivel supranacional que constriñen la autonomía de los tribunales internos ${ }^{68}$, circunstancia de la que nos ocuparemos más adelante.

Tales límites se justifican por la función de salvaguardia de los valores fundamentales de la Unión consagrados en el art. 2 TUE, así como por la necesidad de contribuir a la consecución de los objetivos previstos en el art. 3 TUE, que son inherentes a las disposiciones y principios de orden público de su ordenamiento jurídico. El TJ ha corroborado dichas funciones al reconocer también la validez de la aplicación de ciertas disposiciones del orden público supranacional extraterritorialmente ${ }^{69}$.

\section{LA NOCIÓN DE INTERÉS PÚBLICO Y SU FUNCIÓN EN EL ORDENAMIENTO DE LA UE}

Como de forma expresa establecen varias previsiones normativas del derecho de la Unión y alguna sentencia del TJ, existe una relación funcional entre las nociones de orden público e interés público que no empaña su claro deslinde conceptual dentro del propio ordenamiento que nos ocupa ${ }^{70}$.

ordine publico nationale: Sustituzione, integrazione o coesistenza?», L'Ordine Pubblico nel Diritto dell'Unione Europea, Guiffrè Editore, Milano, 2012, pp. 350-356.

66 Véase, por ejemplo, la sentencia del TJ Aladzhov, C-434/10, EU:C:2011:750, apdo.34.

67 Conclusiones de la Abogado General Kokott en el asunto ASfly y LAL, C-302/13, EU:C:2014:2046, punto 84.

68 Véanse, entre otras, la sentencia Trade Agency EU:C:2012:531, apdo. 49, y jurisprudencia que se cita, y, la sentencia ASfly y LAL cit., EU:C:2014:2319, apdo. 47, y jurisprudencia que se cita.

69 Véase la sentencia del TJ Owusu, C-281/02, EU:C:2005:120, apdos. 32-35, especialmente apdo. 34.

70 Así, por ejemplo, las conclusiones de la Abogado General Trstenjak en el asunto Comisión/Luxemburgo, C-319/06, EU:C:2007:516, punto 44, que afirma que «el concepto de orden público fue objeto de una precisión mediante la Declara- 
El interés público es una noción concretada mediante disposiciones normativas que tutelan o protegen bienes jurídicos que forman parte de políticas públicas $^{71}$, tal y como se establece, por ejemplo, en la letra a) del apartado primero del art. 4 (Excepciones) del Reglamento (CE) 1049/2001 del Parlamento Europeo y del Consejo ${ }^{72}$, o en el apartado cuarto del art. 21 del Reglamento (CE) 139/2004 del Consejo ${ }^{73}$, así como mediante su consagración en la jurisprudencia del TJ y del TG.

ción núm. 10 del Consejo y de la Comisión sobre la Directiva 96/71 [...] e incluye las disposiciones obligatorias a las que no puede hacerse excepción y que, por su naturaleza y objetivo, responden a exigencias imperativas del interés público». De forma similar, la sentencia del TJ Omega, C-36/02, EU:C:2004:614, en cuyos apdos. 35-36, al establecer que la protección de los derechos fundamentales, tanto a nivel de la Comunidad como de sus Estados miembros, es un interés legítimo que puede justificar restricciones a las libertades comunitarias, especifica igualmente que, dichas medidas restrictivas, sólo pueden fundamentarse en razones de orden público, si son necesarias para la protección de los intereses (públicos) que pretenden garantizar.

71 Por ello, también puede contraponerse en determinadas circunstancias frente al mero interés particular como por ejemplo establece la sentencia del TG de 25 de marzo de 2015, Sea Handling, T456/13, EU:T:2015:185, apdos. 105 y 106 y jurisprudencia que se cita; igualmente, la sentencia del TG de 24 de marzo de 2011, Navigazione Libera del Golfo, T-109/05 y T-444/05, EU:T:2011:235, apdo. 148. Sobre la aplicación de las disposiciones de interés público en el ámbito de la normativa europea relativa a la propiedad intelectual, véase Viola PRIFTI, The Role of Public Interest in Plant-Related Patents: A European Perspective, Max Planck Institute for Innovation and Competition, December 24, 2014.

72 Reglamento de 30 de mayo de 2001 relativo al acceso del público a los documentos del Parlamento Europeo, del Consejo y de la Comisión (DO L 145, de 31 de mayo de 2001), p. 43. Un análisis sobre el alcance de esta disposición en Gintaré MAKAUSKAITE, «Public Interest in the Context of the Right to Access Official Information", Baltic Yearbook of International Law Online, vol. 11, núm. 1, 2011, pp. 281-306.

73 Reglamento de 20 de enero de 2004 sobre el control de las concentraciones entre empresas (DO L 24 de 29.1.2004, p. 1). Como de forma reiterada ha establecido la jurisprudencia del TJ, no podrán adoptarse medidas que restrinjan u obstaculicen la aplicación del Derecho de la Unión que estén fundadas en razones genéricas o imprecisas de salvaguardia del interés público, como, por ejemplo, el interés en reforzar la estructura competitiva del mercado de que se trate; véase la sentencia del TJ Comisión /República Portuguesa, C171/08, EU:C:2010:412, apdos. 70, $76-77$ y jurisprudencia que se cita. Esta doctrina clarifica y previene frente a la utilización discrecional de las disposiciones legislativas internas de los Estados miembros para oponerse a fusiones 
Ello resulta especialmente reseñable en el ámbito de la política de protección de los consumidores, donde el TJ ha establecido, por ejemplo, que el art. 4 de la Directiva 85/577/CEE del Consejo ${ }^{74}$ «encierra un interés público que [...] puede justificar una intervención positiva del juez nacional con el fin de subsanar el desequilibrio existente entre el consumidor y el comerciante en el marco de los contratos celebrados fuera de los establecimientos comerciales ${ }^{75}$ ». Una afirmación similar ha tenido lugar con relación al apartado primero del art. 7 de la Directiva 93/1376, y con relación al art. 1, apartado segundo, letra a) de la Directiva 1999/44/CE del Parlamento Europeo y del Consejo, de 25 de mayo de 1999, sobre determinados aspectos de la venta y las garantías de

transfronterizas de las sociedades de capital, tal y como prevé el Considerando tercero de la Directiva 2005/56/CE del Parlamento Europeo y del Consejo, de 26 de diciembre de 2005 (DO L 310 de 25.11.2005, p. 1).

Consiguientemente, deberán interpretarse y aplicarse restrictivamente la invocación de las razones de interés público que, con dicha finalidad, están previstas, respectivamente, en la letra b) del apdo. primero del art. 4 de la citada Directiva, en el apdo. catorce del art. 8 y en el párrafo segundo del art. 19 del Reglamento 2157/2001/CE del Consejo, de 8 de octubre de 2001, por el que se aprueba el Estatuto de la Sociedad Anónima Europea (SE) (DO L 294 de 10.11.2001, p. 1).

74 Directiva de 20 de diciembre de 1985 relativa a la protección de los consumidores en el caso de contratos negociados fuera de los establecimientos comerciales (DO L 372 de 31.12.1985, p. 31).

75 Véase la sentencia del TJ Martín Martín, C-227/08, EU:C:2009:792, apdo. 28. Como el propio TJ indica en este apdo. al remitir a su jurisprudencia citada en el apdo. 20 de la sentencia, concretamente, los asuntos Van Schijndel, cit. EU:C:1995:441, apdo. 21, y Van der Weerd, as. ac. C-222/05 a C-225/05, EU:C:2007:318, apdo. 35, la intervención positiva o de oficio del juez nacional, sólo puede tener lugar por tratarse de casos excepcionales exigidos por el interés público. En este sentido, la Abogado General Trstenjak sostiene sin embargo que el interés público exige garantizar aquí una protección efectiva de los consumidores, razón por la cual, el juez nacional está obligado, y no meramente facultado, para intervenir de oficio. Igualmente, véanse las conclusiones de la Abogado General Trstenjak en el asunto Martín Martín, C-227/08, EU:C:2009:295, puntos 90-91, y las conclusiones del Abogado General Szpunar en el asunto Banco Primus, C-421/14, EU:C:2016:69, punto 47 y jurisprudencia que se cita en la nota 22.

76 Directiva 93/13/CEE del Consejo, de 5 de abril de 1993, sobre las cláusulas abusivas en los contratos celebrados con consumidores (DO L 95 de 21.4.1993, p. 29). Véase también la sentencia del TJ Unicaja Banco, y, Caixabank, as. ac. C-482/13, C-484/13, C-485/13 y C-487/13, EU:C:2015:21, apdo. 30 y jurisprudencia que se cita. 
los bienes de consumo ${ }^{77}$, que impone al juez nacional concernido la obligación de comprobar si el comprador puede tener la condición de consumidor en el sentido de esta Directiva, aunque este no lo haya alegado expresamente, así como en otras disposiciones relevantes ${ }^{78}$.

Por otro lado, dentro del propio marco normativo de la Unión se integra también la noción de «interés público superior», a modo de excepción que ampararía el ejercicio de ciertos derechos por los interesados, aunque estos les hubieren sido denegados previamente por las instituciones europeas concernidas alegando a su vez otras razones fundadas en el interés público ${ }^{79}$.

El TJ ha elaborado una doctrina interpretativa que impone generalmente a las instituciones un deber exhaustivo de la motivación de la preponderancia de los posibles intereses concurrentes sobre el «interés público superior» invocado, al realizar el pertinente análisis comparativo, en los casos en que aquellos denieguen el ejercicio del derecho al interesado ${ }^{80}$. Esta premisa tiene como

77 DO L 171 de 7.7.1999, p. 12. Esta Directiva fue modificada por la Directiva 2011/83/ UE del Parlamento Europeo y del Consejo, de 25 de octubre de 2011, sobre los derechos de los consumidores (DO L 304 de 22.11.2011, p. 64). Véase la sentencia del TJ Fronkje Faber, C-497/13, EU:C:2015:357, apdo. 48. Igualmente, las conclusiones de la Abogado General Sharpston en el asunto Frunkje Faber, EU:C:2014:2403, puntos 68-72, especialmente el punto 70, donde deduce la existencia de una norma de orden público que establece dicha obligación a cargo del juez nacional. Llegando incluso a afirmar en la nota 44 de las citadas conclusiones que esta obligación podría exigirse también en el ámbito de la contratación laboral para proteger a la parte más débil de la relación contractual.

78 No obstante existe cierta difuminación de las lindes conceptuales entre las nociones de orden público, interés público e, incluso, de interés general en el ordenamiento de la Unión, tal y como pone de manifiesto una jurisprudencia posterior, donde se afirma que los objetivos de la protección de los consumidores están fundados en «razones imperiosas de interés general», de conformidad con lo establecido en su doctrina; véanse las sentencias del TJ Itevelesa, C-168/14, EU:C:2015:685, apdo. 74 y jurisprudencia que se cita, y Stanley, C-463/13, EU:C:2015:25, apdo. 48 y jurisprudencia que se cita.

79 Véase, por ejemplo, el último inciso de los apdos. segundo y tercero, párrafos primero y segundo del citado art. 4 del Reglamento (CE) 1049/2001. Igualmente, el párrafo primero del apdo. primero del art. 6 del Reglamento (CE) 1367/2006 de Parlamento Europeo y del Consejo, de 6 de septiembre de 2006, relativo a la aplicación a las instituciones y a los organismos comunitarios del Convenio de Aarhus sobre el acceso a la información, la participación del público en la toma de decisiones y el acceso a la justicia en materia de medio ambiente (DO L 264 de 25.9.2006, p. 13).

80 Véanse las sentencias del TJ Comisión/BWEnergie, C-365/12P, EU:C:2014:112, apdo. 64; y Suecia/Consejo; as. ac. C-39/05P y C-52/05P, EU:C:2008:374 apdo. 49, entre otras. 
contrapeso la exigencia de que la invocación de la existencia de un «interés público superior» se fundamente concisamente, descartándose las alegaciones genéricas o desconectadas de las concretas circunstancias del caso ${ }^{81}$.

\section{LA RELACIÓN ENTRE LAS DISPOSICIONES Y PRINCIPIOS DE ORDEN PÚBLICO Y DE INTERÉS PÚBLICO DE LA UE Y LOS ORDENAMIENTOS INTERNOS DE LOS ESTADOS MIEMBROS}

En su calidad de elementos fundamentales del sistema jurídico de la Unión, las disposiciones y principios de orden público y de interés público deben de aplicarse adecuadamente a nivel interno a efectos de garantizar su efecto útil. Las diversas consecuencias que ello supone inciden tanto en el marco normativo como en la práctica administrativa o en la conducta de los operadores jurídicos, especialmente los jueces, de sus Estados miembros.

En síntesis, el impacto de dichas disposiciones y principios se presenta como las dos caras de una misma moneda. Por un lado, contribuye a la integración de lagunas jurídicas y, por otro, constriñe la discrecionalidad de los poderes públicos a la hora de invocar las nociones de orden público e interés público de los ordenamientos nacionales, adecuándolas al cumplimiento del derecho de la UE.

Como botón de muestra de la primera de ellas, puede citarse la inclusión entre los motivos de orden público susceptibles de ser invocados para la anulación de un laudo arbitral por los órganos jurisdiccionales nacionales, su incompatibilidad con lo dispuesto en las normas sobre competencia del art. 101 TFUE (antiguo art. 81 TCE) ${ }^{82}$.

81 Véase las sentencias del TJ LPN, as. ac. C-514/11P y C -605/11P, EU:C:2013:738, apdo. 93; Comisión/Agrofert, C-477/10P, EU:C:2012:394, apdo. 68, y Comisión/Technische Glaswerke Ilmenau, C-139/07P, EU:C:2010:376, apdo. 62, entre otras. Con relación al acceso de los interesados a documentos de las instituciones y órganos de la Unión, véanse, entre otras, las sentencias del TG de 12 de mayo de 2015, Technion, T/480/11, EU:T:2015:272, apdo. 79, y jurisprudencia que se cita; de 7 de julio de 2015, Axa Versicherung AG, T-677/13, EU:T:2015:473, apdos. 69 y 70 y la jurisprudencia que se cita; de 23 de septiembre de 2015, Client Earth, T-245/11, EU:T:2015:675, apdos. 193-196, y de 13 de noviembre de 2015, Client Earth, as. ac. T-424/14 y T-425/14, EU:T:2015:848, apdos. 150154; etc.

82 Véase la Sentencia del TJ Eco Swiss, EU:C:1999:269, apdos. 36-39. Según sostiene el Abogado General Saggio en las conclusiones presentadas en este asunto, se trataría de insertar las normas comunitarias sobre la competencia en el ámbito de las normas de «orden público», ampliando así el ámbito de aplicación de las disposicio- 
Resulta igualmente incompatible con la imperatividad que se deriva del principio general de la jurisprudencia del TJ, según el cual, cada órgano jurisdiccional que entiende de una demanda determina, por sí solo y según las normas aplicables, si es competente para resolver el litigio que se le somete, una orden conminatoria dictada por un órgano jurisdiccional de otro Estado miembro por la que se prohíbe a una parte entablar un procedimiento que no sea de arbitraje o proseguir un procedimiento ante un órgano jurisdiccional de otro Estado miembro ${ }^{83}$.

Ello resulta especialmente necesario para la salvaguardia del orden público de la UE que consagra el principio de tutela judicial efectiva entre los derechos fundamentales protegidos en su ordenamiento jurídico, ya que el respeto al mencionado principio de competencia jurisdiccional garantiza al

nes internas relevantes que permiten el examen jurisdiccional de un laudo también por motivos de "orden público comunitario», EU:C:1997:97, punto 38. Entre la literatura que analiza el relevante impacto de la Sentencia Eco Swiss, véanse: Santiago ÁLVAREZ GONZÁLEZ, "Arbitraje comercial internacional, orden público y Derecho Comunitario de la Competencia», La Ley, 1999, vol. 5, pp. 1893-1898; Sylvaine, POILLOT-PERUZZETTO, «L'ordre public international en droit communautaire. A propos de l'arrêt de la Cour de Justice des Communautés du 1er juin 1999, (affaire Eco Swiss China Time Ltd), Journal du droit international, 2000, pp. 299-307; Stefano BASTIANON, «L'arbitrabilità delle controversie antitrust tra diritto nazionale e diritto comunitario", Il Foro italiano, vol. 4, 1999, pp. 471-483; Alexis MOURRE, «Les rapports de l'arbitrage et du droit communitaire après l'arrêt, Eco Swiss de la Cour de Justice des Communautés Européennes, Gazette du Palais, III, Doct. 2000, pp. 127-132; Sacha PRECHAL y Natalya SHELKOPLYAS, «National Procedures, Public Policy and EC Law. From Van Schijndel to Eco Swiss and Beyond», European Review of Private Law, núm. 5, 2004, pp. 589-611, y Luca G. RADICATI DI BROZOLO, «Arbitrato, diritto della concorrenza, diritto comunitario e regole di procedura nazionali», Rivista dell'arbitrato, vol. 4, 1999, pp. 665-697.

83 Véase la sentencia del TJ Allianz, C-185/07, EU:C:2009:69, apdos. 29 y 30. Esta sentencia suscitó algunas posiciones críticas doctrinales por su aparente colisión con la práctica vigente en el ámbito del arbitraje internacional. Cabe reseñar, entre otras, las de Mario NICOLELLA, «Condamnation de la practique de l'anti-suit injunction par le biais de l'effet utile du droit communautaire», Gazette du Palais, núm. 188189, I. Jur., 2010, pp. 21-22; Catherine KESSEDJIAN, «Arbitrage et droit européen: une désunion irrémédiable?», Recueil Le Dalloz, núm. 14, 2009, pp. 981-985; Edwin PEE, "Arbitration and Anti-Suit Injunctions in the European Union", Law Quaterly Review, vol. 125, 2009, pp. 365-369; Arnaud VAN WAEYENBERGE, «Le juge communautaire face au «Common Law». Réflexions autour de l'arrêt «Allianz», Revue $d u$ droit de l'Union européenne, núm. 2, 2009, pp. 291-303. 
demandante que considera un convenio arbitral ineficaz o inaplicable el derecho a litigar ante un órgano jurisdiccional interno ${ }^{84}$.

A mayor abundamiento, el Tribunal exige actuar con diligencia a los interesados cuando establece que, si comprueba la posible existencia de una violación manifiesta del orden público de la Unión en el Estado requerido, el juez de este Estado debe tener en cuenta que, salvo que existan circunstancias que impidan el ejercicio de los recursos en el Estado miembro de origen, los justiciables deben utilizar todos los recursos disponibles para prevenir la violación en un nivel superior ${ }^{85}$. El asunto Meroni confirma esta jurisprudencia

84 Conclusiones de la Abogado General Kokott en el asunto Allianz, EU:C:2008:466, punto 41. Tal y como establece una jurisprudencia posterior del TJ, el que un tribunal arbitral prohíba a una parte formular determinadas pretensiones ante un órgano jurisdiccional de un Estado miembro, no impide que ésta pueda beneficiarse de la tutela judicial ya que, corresponde a dicho órgano jurisdiccional determinar si procede o no reconocer y ejecutar el laudo, lo cual abre la posibilidad de que esa parte pueda oponerse a tal reconocimiento y ejecución; sentencia del TJ «Gazprom» OAO, C-536/13, EU:C:2015:316, apdo. 38. No resultaría necesario establecer como fundamento de la imperatividad del citado principio las disposiciones aquí relevantes del Reglamento (CE) 44/2001 del Consejo, de 22 de diciembre de 2000, relativo a la competencia judicial, el reconocimiento y la ejecución de resoluciones judiciales en materia civil y mercantil («Reglamento Bruselas I») (DO L 12 de 16.1.2001, p. 1), que actualmente está refundido en el Reglamento (UE) 1215/2012 del Parlamento Europeo y del Consejo de 12 de diciembre de 2012, relativo a la competencia judicial, el reconocimiento y la ejecución de resoluciones justiciables en materia civil y mercantil (DO L 351 de 20.12.2012, p. 1). Véanse las conclusiones del Abogado General Wathelet en el asunto «Gazprom» OAO, EU:C:2014:2414, puntos 178-181. Un análisis doctrinal del asunto «Gazprom» OAO en Carlos GONZÁLEZ BUENO y Laura LOZANO, «Anti-suit Injunction: where does Gazprom leave us?», Spain Arbitration Review, núm. 24, 2015, pp. 91-103, especialmente 97-100.

85 Sentencia del TJ Diageo Brands, C-681/13, EU:C:2015:471, apdo. 68 párrafo segundo. Esta jurisprudencia confirma la que se estableció en el asunto Renault, donde el TJ determinó que el Juez del Estado requerido no puede denegar el reconocimiento de la decisión controvertida por el mero hecho de considerar que se aplicó mal el derecho nacional o el derecho comunitario, subrayando a su vez que el sistema de recursos interno completado con el mecanismo de la remisión prejudicial otorga a los justiciables una garantía suficiente; véase la sentencia del TJ Renault, C-38/98, EU: C:2000:225, apdo. 33. Cabe reseñar en este sentido que el Tribunal otorga una protección cualificada al agotamiento de las vías procesales por los justiciables, tal y como establece, por ejemplo, al afirmar en otro asunto que las transacciones ejecutorias destinadas a terminar un litigio, aun celebradas ante un juez, tienen un carácter esencialmente contractual y no pueden impedir el reconocimiento y la ejecución de una resolución 
al establecer que no cabe considerar manifiestamente contrarios al orden público del Estado miembro requerido, ni al derecho a un proceso equitativo, en el sentido del art. 47 CDFUE y del apartado primero del art. 34 del citado Reglamento 44/2001, el reconocimiento y la ejecución de un auto dictado por un juez de un Estado miembro sin oír a un tercero cuyos derechos son susceptibles de verse afectados por dicho auto, siempre que pueda invocar sus derechos ante ese juez ${ }^{86}$.

Por otro lado, una constante jurisprudencia del TJ constriñe la discrecionalidad de los poderes públicos de los Estados miembros cuando interpretan o aplican inadecuadamente restricciones al ejercicio de los derechos y libertades consagrados en el sistema jurídico de la UE, amparándose en las nociones internas de orden público, seguridad o interés público.

Los criterios utilizados por el Tribunal con esta finalidad siguen un canon mediante el cual las justificaciones a las medidas internas controvertidas fundadas en dichas nociones son objeto de una interpretación restrictiva y deben referirse a una amenaza real y suficientemente grave que afecte a un interés esencial de la sociedad ${ }^{87}$.

Ciertamente, el control de legalidad no se limita aquí a determinar la compatibilidad con las disposiciones y principios de orden público de la Unión, sino que persigue garantizar el efecto útil de las normas supranacionales de que se trate ${ }^{88}$. La jurisprudencia relevante a estos efectos se ha pronun-

judicial dictada en un litigio entre las mismas partes en otro Estado contratante; véase la sentencia del TJ Solo, C-414/92, EU:C:1994:221, apdos. 17-20.

Véase la sentencia del TJ Meroni, C-559/14, EU:C:2016:349, apdos. 48-54 y jurisprudencia que se cita. Un comentario crítico a esta sentencia en Cyril NOURISSAT, "Jeu de l'exception d'ordre public en matière d'exécution transfontière dans l'espace intra-européen: inversión ou perversion du contentieux après l'arrêt Meroni?», disponible en: http://www.gdr-elsj.eu/tag/ordre-public/ (consultado el 5 de junio de 2016).

87 Véase, por ejemplo, el auto del presidente del TG de 27 de febrero de 2015, España/ Comisión, T-826/14R, EU:T:215:126, apdos. 25 y 48, y jurisprudencia que se cita; igualmente, la sentencia del TJ Comisión/España, C-114/97, EU:C:1998:519, apdos. 46 y 47 , etc.

88 Así, por ejemplo, el TJ determinó que en el ámbito de aplicación del Convenio sobre la competencia judicial y la ejecución de resoluciones judiciales en materia civil y mercantil, de 27 de septiembre de 1968, (DO L 299 de 31.12.1972, p. 321), sustituido por el Reglamento (UE) 1215/2012 del Parlamento Europeo y del Consejo, de 12 de diciembre de 2012, (DO L 351 de 20.12.2012, p. 1), la previsión del apdo. primero del art. 27 del convenio relativa al no reconocimiento de resoluciones extranjeras por ser contrarias al orden público interno, tiene un carácter excepcional, correspondiendo además a los jueces nacionales velar por la aplicación coherente y autónoma 
ciado, entre otras cuestiones, con relación a los obstáculos frente al ejercicio del derecho a la libertad de establecimiento ${ }^{89}$, a la libre prestación de servi$\operatorname{cios}^{90}$, y a la libre circulación de capitales ${ }^{91}$.

del conjunto de sus disposiciones; véase la sentencia del TJ Hoffmann, C-145/86, EU:C:1988:61, apdos. 21, 25 y 29-31. Al contrario, la aplicación de la citada previsión de orden público es posible en ciertos supuestos excepcionales, como, por ejemplo, cuando sea necesaria para proteger un derecho fundamental del interesado; véase la sentencia del TJ Krombach, C-7/98, EU:C:2000:164, apdos. 23-27, 35 y 44-45. Igualmente, las conclusiones del Abogado General Saggio en el asunto Krombach, EU:C:1999:446, puntos 20-28. Aunque una jurisprudencia posterior confirma esta doctrina, véase la sentencia del TJ Gambazzi, C-394/07, EU:C:2009:2019, apdos. 26-29 y 48, y las conclusiones de la Abogado General Kokott en el asunto Gambazzi, EU:C:2008:748, puntos 67, 73 y 76; no obstante, el Tribunal ha precisado su alcance al establecer que, los derechos fundamentales no constituyen prerrogativas absolutas, sino que pueden implicar restricciones, especialmente los derechos procesales, siempre que respondan efectivamente a objetivos de interés general perseguidos por las medidas de que se trate y no menoscaben manifiesta y desproporcionadamente el derecho garantizado. En este sentido, la tutela del derecho de defensa del interesado debe ponderarse junto con los de la tutela judicial efectiva y la celeridad procesal, por lo que podría justificarse la ejecución por un juez en un Estado miembro requerido de una resolución judicial dictada en rebeldía por un órgano jurisdiccional de otro Estado miembro, sin que sea posible denegarla alegando motivos fundados en una grave infracción de orden público; véase la sentencia del TJ Trade Agency, EU:C:2012:531, apdos. 55-62. Igualmente, las conclusiones de la Abogado General Kokott en el asunto Trade Agency, EU:C:2012:247, puntos 77-81.

89 Así, por ejemplo, ha declarado incompatible con el art. 49 del TFUE una normativa de un Estado miembro que exige a los transportistas extranjeros, establecidos mediante una sucursal en dicho Estado, obtener una licencia especial otorgada discrecionalmente por las autoridades competentes, para ejercer el transporte urbano colectivo, sin concretar las razones de orden público o interés público que podrían justificarla; véase el auto del TJ Slovenská autobusová, C-318/14, EU:C:2015:352, apdos. 4350 y jurisprudencia que se cita. Igualmente, véase la sentencia del TJ National Grid, C-371/10, EU:C:2011:785, apdos. 43 y 84-85; etc. Por otro lado, cabe reseñar igualmente cierta jurisprudencia que protege expresamente y de manera conjunta el efecto útil de disposiciones de derecho derivado destinadas a garantizar el ejercicio de la libertad de establecimiento y el juego de una competencia no falseada en el mercado interior; véase, por ejemplo, la sentencia del TJ Ingmar, C-381/98, EU:C:2000:605, apdos. 24 y 25. Algún autor mostró su discrepancia con el argumento principal de la citada sentencia que reconoce «esencial» para el ordenamiento comunitario la protección de ambos objetivos y su consiguiente aplicación a una situación que tenga una relación estrecha con el territorio de la Unión, aun cuando afecte a nacionales 
Capítulo aparte merece el análisis de la jurisprudencia del TJ cuando se ocupa de remover las trabas a la libre circulación de trabajadores y a la libre

de terceros Estados que pretenden prevalerse de una cláusula de elección de la ley aplicable para someterla a la jurisdicción de un país tercero; véase, por ejemplo, Albert FONT I SEGURA, «Reparación indemnizatoria tras la extinción del contrato internacional de agencia comercial: imperatividad poliédrica o el mito de Zagreo», Revista de Derecho Comunitario Europeo, núm. 9, 2001, pp. 259-279; igualmente, H.L.E. (Rick) VERHAGEN, «The tension between party autonomy and European Union Law: Some observations on Ingmar, International Comparative Law Quaterly, vol. 5, núm.1, 2002, pp. 135-154, etc. Véase, igualmente, la sentencia del TJ Honyvem, C-465/04, EU:C:2006:199, apdos. 22-24.

90 En el ámbito de aplicación de la Directiva 2006/123/CE del Parlamento Europeo y del Consejo, de 12 de diciembre de 2006, relativa a los servicios en el mercado interior, (DO L 376 de 27.12.2006, p. 36), ha establecido la posibilidad de que el legislador comunitario limite expresamente la aplicación de medidas internas fundadas en razones de orden público o interés público, cuando adopte normas de derecho derivado que desarrollen las libertades económicas fundamentales reconocidas en las disposiciones del TFUE; véase la sentencia del TJ Rina Services, C-593/13, EU:C:2015:399, apdos. 32-41. Igualmente, la sentencia del TJ Laezza, C-375/14, EU:C:2016:60, en la que, aun considerando la lucha contra la criminalidad vinculada a los juegos de azar como un posible objetivo que justifique restricciones a los arts.49 TFUE y 56 TFUE por razones imperiosas de interés general, considera ilegal, por desproporcionada, la normativa interna adoptada para presentarlo, apdos. 32-35 y 44. Recuérdese que el TJ ya había establecido anteriormente la necesidad de garantizar el efecto útil de los antiguos arts.59 y 60 del Tratado CEE, de 25 de marzo de 1957, por el que se constituye la Comunidad Económica Europea, actuales arts.56 y 57 del TFUE, declarando incompatibles ciertas medidas internas, leyes de policía y de seguridad, claramente desproporcionadas; véase la sentencia del TJ Arblade, as. ac. C-369/96, y C-376/96, EU:C:1999:575, apdo. 80. Igualmente, las conclusiones del Abogado General Ruiz Jarabo en el asunto Arblade, EU:C:1998:318, puntos 84-88. Asimismo, el Tribunal, ha declarado la ilegalidad de las medidas internas fundadas en las citadas razones y que tienen por efecto dificultar más la prestación de servicios entre Estados miembros, que a nivel meramente interno de un Estado miembro; véase la sentencia del TJ Comisión/Dinamarca, C-150/04, EU:C:2007:69, apdo. 38; etc.

91 Por ejemplo, véase la sentencia del TJ Comisión/República Portuguesa, EU:C:2010: 412, apdos. 76-77 y jurisprudencia que se cita. Sobre las consecuencias negativas para la libre circulación de capitales derivadas de una utilización inadecuada de la reserva de «interés público» por los Estados miembros de la Unión, y, especialmente en lo concerniente a su impacto negativo en operaciones de fusión y adquisición de empresas, véase Alison JONES y John DAVIES, «Merger control and the public interest: balancing EU and national law in the protectionist debate», European Competition Journal, vol. 10, núm. 3, 2014, pp. 453-497, especialmente 457-458, 462-465 y 469-491. 
circulación de personas, ya que, dada su estrecha vinculación con cuestiones que generalmente afectan también, directa o indirectamente, al ejercicio de los derechos fundamentales, el Tribunal se muestra extremadamente riguroso a la hora de realizar los pertinentes controles de legalidad de las medidas internas controvertidas ${ }^{92}$.

Consiguientemente, se eleva el umbral de exigibilidad en lo concerniente a la delimitación de las causas objetivas que justifican las medidas internas controvertidas, a su adecuación al principio de no discriminación por razón de nacionalidad y a su carácter proporcionado. Estas salvaguardas pretorianas han configurado progresivamente un régimen de garantías pro hómine en el que la admisibilidad de las restricciones se pondera mediante un análisis de la conducta personal del justiciable, admitiendo exclusivamente como criterios relevantes a tal efecto la existencia de motivos graves de orden público y seguridad públicas ${ }^{93}$. A mayor abundamiento, en situaciones en las que autoridades internas aleguen un supuesto de amenazas fundadas en «motivos imperiosos» de seguridad nacional u orden público para justificar una medida de expulsión, el Tribunal establece el deber de los órganos jurisdiccionales nacionales de verificar exhaustivamente la veracidad de tales argumentos, si el interesado disfruta del estatuto de refugiado o del estatuto de protección subsidiaria ${ }^{94}$.

92 Véase, por ejemplo, la sentencia del TJ Benallal, C-161/15, EU:C:2016:175, apdos. 22-25 y 30-35, y jurisprudencia que se cita; la sentencia del TJ Carpenter, C-60/00, EU:C:2002:434, apdo. 41; la sentencia del TJ Orfanopoulos, as. ac. C-482/01 y C-493/01, EU:C:2004:262, apdo. 99, etc. Un análisis sobre la relevancia de la tutela de los derechos fundamentales y el orden público supranacional en Matej AVBELJ, «Security and the transformation of the EU Public Order», German Law Journal, vol. 14, núm. 10, 2013, pp. 2057-2073.

93 Véase, por ejemplo, la sentencia del TJ P.I, C-348/0P, EU:C:2012:300, apdos. 30-34; igualmente, las conclusiones del Abogado General BOT en el asunto P.I, EU:C:2012:123, puntos 41-47, y jurisprudencia que se cita. Véase también la sentencia del TJ Tsakouridis, C:145/09, EU:C:2010:708, apdos. 43-55 y jurisprudencia que se cita. Un análisis doctrinal en Isabel VILLAR FUENTES, «Motivos graves de orden público, una excepción a la protección reforzada contra la expulsión de ciudadanos comunitarios con 10 años de residencia en el Estado de acogida", Revista Internacional de Doctrina y Jurisprudencia, vol. 4, 2013, disponible en: http://www.ual.es/revistas/ RevistaInternacionaldeDoctrinayJurisprudencia/vol4-201312.html.

94 Sentencia del TJ H.T., C-373/13, EU:C:2015:413, apdos. 90-99; igualmente las conclusiones de la Abogado General Sharpston en el asunto H.T., EU:C:2014:2218, puntos 86-103 y jurisprudencia que se cita. En nada empaña esta doctrina una jurisprudencia posterior del TJ que establece que el derecho a enviar a un solicitante de 


\section{EL JUEZ NACIONAL DE MEDIDAS CAUTELARES Y LA TUTELA DEL ORDEN PÚBLICO Y DEL INTERÉS PÚBLICO DE LA UE}

Junto con las importantes atribuciones procesales que en términos generales reconoce la doctrina del TJ a los jueces nacionales para facilitar la tutela cautelar de los derechos y libertades establecidos en el ordenamiento jurídico de la UE, se configura también un régimen más específico al referirse a la salvaguardia de sus disposiciones y principios de orden público e interés público.

Se trata en este caso de conferir una dimensión procesal interna lo más adecuada posible al principio de efectividad del derecho de la Unión para proteger el efecto útil de aquellas normas supranacionales cuyo carácter fundamental las convierte en elementos integrantes del orden público y del interés público, exigiendo por ello una diligencia mayor en la tutela a cargo del órgano jurisdiccional concernido ${ }^{95}$. La obligación de garantizar la correcta aplicación del derecho de la Unión se refuerza aquí con el deber de evitar una violación de sus elementos fundamentales, ya que el nivel de protección ha de ser idéntico en todos los Estados miembros ${ }^{96}$.

Los criterios que configuran el mencionado régimen se han determinado principalmente en diversas sentencias sobre asuntos relativos a la aplicación del derecho de la competencia y de las normas en materia de protección de los consumidores y en materia de cooperación judicial.

protección internacional a un tercer Estado seguro, también puede ser ejercido por un Estado miembro después de que este haya asumido la responsabilidad del examen de la solicitud de protección del interesado; véase la sentencia del TJ Mirza, C-695/15 PPU, EU:C:2016:188, apdos. 48-53 y 60-63. Similarmente, el Tribunal consideró adecuada al derecho de la UE una medida de internamiento de un solicitante de protección internacional en un Estado miembro por razones de la protección de la seguridad nacional y del orden público, véase la sentencia del TJ J.N., C-601/15 PPU, EU:C:2016:84, apdos. 71-81.

95 Véase, la sentencia Van der Weerd, EU:C:2007:318, apdos. 35-41 y jurisprudencia que se cita; igualmente, las conclusiones del Abogado General Poiares Maduro en el asunto Van der Weerd, EU:C:2007:124, puntos 26-29, especialmente el punto 29 donde afirma que, si bien el principio de efectividad no impone al juez nacional formular de oficio un motivo basado en una disposición fundamental del ordenamiento de la Unión, el tribunal nacional debe tener la facultad de formularlo de oficio si las partes no tuvieran una oportunidad real de hacerlo.

96 Véanse las conclusiones del Abogado General Szpunar en el asunto Diageo Brands, EU:C:2015:137, punto 65 . 


\section{LA TUTELA DEL ORDEN PÚBLICO Y EL DERECHO DE LA COMPETENCIA DE LA UE}

En lo concerniente al primero de estos ámbitos además del deber que incumbe a todos los órganos jurisdiccionales nacionales de excluir la aplicación de normas internas que impiden a una parte en un procedimiento administrativo o judicial ejercer los derechos que le confiere una disposición de orden público del derecho de la competencia europeo, tanto frente a otros particulares como frente a las autoridades públicas ${ }^{97}$, el juez nacional de medidas cautelares debería decretar, en su caso, cuantas medidas resultaran pertinentes para preservar el efecto útil del derecho de la Unión, incluida la posibilidad de reparar económicamente el daño injustamente causado en circunstancias excepcionales para el demandante ${ }^{98}$.

Este último extremo ha sido confirmado implícitamente por el TJ en la sentencia ASfly y LAL, antes citada, al establecer la legalidad de una medida provisional y cautelar de embargo preventivo de ciertos bienes adoptada por un órgano jurisdiccional de Lituania como reclamación indemnizatoria por los daños y perjuicios derivados de la violación de los antiguos arts. $81 \mathrm{CE}$ y $82 \mathrm{CE}$, actuales arts. 101 TFUE y 102 TFUE, y cuya ejecución en Letonia se cuestionaba, entre otros motivos, por su presunta incompatibilidad con el orden público interno ${ }^{99}$.

Cabe reseñar sobre el particular la referencia a los criterios mediante los que debe motivarse una medida provisional y cautelar en lo que respecta a la fijación del importe de las sumas indemnizatorias, ya que, estas se considerarán aquilatadas a las exigencias de un proceso equitativo si el órgano jurisdiccional en cuestión sigue un razonamiento claro que permita a las partes entenderlo y, en su caso, interponer un recurso contra el auto en el que la decide ${ }^{100}$.

\section{LA TUTELA DEL INTERÉS PÚBLICO Y LA PROTECCIÓN DE LOS CONSUMIDORES EN EL DERECHO DE LA UE}

Dentro del ámbito de la política de protección de consumidores, habida cuenta de que, como ya se ha reseñado, la relevancia del interés público que

97 Véase la sentencia del TJ Consorzio Industrie Fiammiferi (CIF), C-198/01, EU:C:2003:430, apdo. 49; igualmente, las conclusiones del Abogado General Jacobs en el asunto Consorzio Industrie Fiammiferi (CIF), EU:C:2003:58, punto 44.

98 Sigo en este sentido a Alison JONES y John DAVIES, op. cit., p. 490.

99 Véase la sentencia ASfly y LAL cit., apdos. 15-18, 39 y 49-59.

100 Ibid., apdos. 49-54; igualmente, las conclusiones de la Abogado General Kokott en el asunto ASfly y LAL cit., puntos 70-82, especialmente los puntos 80-82. 
atañe a diversas disposiciones normativas de derecho derivado justifican la atribución de un conjunto de obligaciones a cargo de los jueces nacionales, se ha establecido igualmente la posibilidad de ejercer las correspondientes actuaciones judiciales destinadas a preservar los derechos del consumidor con independencia de la naturaleza del procedimiento judicial de que se trate ${ }^{101}$.

Ello incluye la adopción de medidas cautelares destinadas a lograr la efectividad de la protección que se pretende garantizar mediante dichas disposiciones, siempre que resulten necesarias para la consecución de la plena eficacia de la decisión judicial que zanje la controversia ${ }^{102}$. Consiguientemente, el TJ se abstendrá de pronunciarse en los asuntos que no le hayan sido planteados coherentemente por el juez nacional de remisión ${ }^{103}$.

Se desprende de un análisis cabal del acervo doctrinal del TJ que establece las pautas de actuación de los órganos jurisdiccionales internos a los efectos de preservar el efecto útil de estas disposiciones ${ }^{104}$, que el juez nacional de medidas cautelares puede desempeñar aquí un papel fundamental. Ciertamente, si se trata de un litigio entablado exclusivamente entre particulares, deberá realizar una interpretación conforme de las mismas que tome en consideración todas las normas internas relevantes, respetando los límites establecidos al efecto; a saber, los principios generales del derecho y la imposibilidad de que ello suponga una interpretación contra legem del derecho nacional ${ }^{105}$. No obstante, para garantizar la plena eficacia de las disposiciones relevantes, deberá

101 Véase la sentencia del TJ Pannon, C-243/08, EU:C:2009:350, apdo. 34. Igualmente, las conclusiones de la Abogado General Sharpston en el asunto Radlinger a.s., C-377/14, EU:C:2015:769, punto 39.

102 Véase la sentencia del TJ, Aziz, EU:C:2013:164, apdos. 52, 59 y 63-64. Una posición crítica que defiende el respeto de la singularidad de los ordenamientos procesales internos en Verica TRSTENJAK, «Procedural Aspects of European Consumer Protection Law and the Case Law of the CJEU from the Perspective of Insurance Law», European Review of Private Law, vol. 21, 2, 2013, pp. 451-478.

103 Véase, por ejemplo, el auto del TJ Garzón Ramos, ECLI:EU:C:2016:112, apdos. 22-28 y jurisprudencia que se cita, en el que se declara incompetente para dirimir si el art. 47 CDFUE se opone a una disposición nacional que impide que el juez de fondo de una demanda de nulidad de título ejecutivo que fundamenta un procedimiento de ejecución hipotecaria, suspenda provisionalmente dicho procedimiento, pendiente ante el juez de ejecución, por no demostrarse la relación con el derecho de la Unión.

104 Véase, por ejemplo, la sentencia del TJ Pénzügyi Lízing, C-137/08, EU:C:2010:659, apdos. 48-52 y 56, y jurisprudencia que se cita.

105 Véase la sentencia del TJ Kásler y Rabai, C-26/13, EU:C:2014:282, apdos. 64 y 65 y jurisprudencia que se cita. 
verificar la adecuación de la normativa interna controvertida a los principios de equivalencia y de efectividad del derecho de la Unión ${ }^{106}$.

Una reiterada jurisprudencia en materia de préstamos hipotecarios así lo corrobora tanto a la hora de declarar la legalidad de las normas nacionales controvertidas $^{107}$, como a la hora de determinar su incompatibilidad con las disposiciones relevantes del derecho de la Unión ${ }^{108}$.

$\mathrm{Al}$ hilo de esta doctrina pueden extraerse indicaciones vinculantes para las actuaciones de los órganos jurisdiccionales de los Estados miembros cuando tengan que decidir si otorgan medidas cautelares demandadas por las partes para que se apliquen las disposiciones de interés público del ordenamiento de la Unión sobre protección de los consumidores, y también cuando tengan que actuar de oficio si resulta necesario para garantizar su efecto útil ${ }^{109}$. Así, por ejemplo, en lo que se refiere a las consecuencias derivadas de la apreciación del carácter abusivo de una cláusula contractual los jueces nacionales no están

106 Véase el Auto del TJ Kovozber, C-120/15, EU:C:2015:730, apdo. 32 y jurisprudencia que se cita. Igualmente, la sentencia del TJ Asociación de Consumidores Independientes de Castilla y León, C-413/12, EU:C:2013:800, apdo. 30 y jurisprudencia que se cita; y, las conclusiones del Abogado General Mengozzi en el asunto Asociación de Consumidores Independientes de Castilla y León, EU:C:2013:532, punto 37.

107 Por ejemplo, la sentencia del TJ Sánchez Morillo, C-539/14, EU:C:2015:508, apdos. 33-41 y 45-49 y jurisprudencia que se cita; la sentencia del TJ Banco Grupo Cajatres, C-90/14, EU:C:2015:465, apdos. 35-42, y jurisprudencia que se cita; el Auto del TJ Banco Bilbao Vizcaya Argentaria, C-602/13, EU:C:2015:397, apdos. 33-39 y 47-54 y jurisprudencia que se cita.

108 Así, por ejemplo, el auto del TJ Ibercaja Banco, C-613/15, EU:C:2016:195, apdos. 28-34 y 40-41, y jurisprudencia que se cita; igualmente, la sentencia del TJ Banco Bilbao Vizcaya Argentaria, C-8/14, EU:C:2015:731, apdos. 26-42 y jurisprudencia que se cita. Entre la literatura que ha analizado las consecuencias de ambas líneas de interpretación en la jurisprudencia del Tribunal de Justicia, véase Federico DELLA NEGRA, «The Uncertain Development of the Case Law on Consumer Protection in Mortgage Enforcement Proceedings: Sánchez Morcillo and Kusionová», Common Market Law Review, vol. 52, 4, 2015, pp. 1009-1032.

109 Ya se ha reseñado el alcance de esta facultad de los órganos jurisdiccionales internos a partir de su atribución por el TJ en la sentencia Martín Martín, EU:C:2009:792, apdo. 28. Un análisis en Malo DEPINCE, «Arrêt Martín Martín: Le juge national peut Soulever d'office les mesures protectrices du consommateur en matière de démarchage», Revue européenne de Droit de la Consommation/European Journal of Consumer Law, núm. 11/2, 2011, pp. 383-391. 
facultados para modificar su contenido, ni para reducir el importe de la pena convencional impuesta al consumidor ${ }^{110}$.

Pero la dimensión más relevante de la doctrina que nos ocupa es la concerniente al progresivo empoderamiento de los órganos jurisdiccionales internos cuando las normas nacionales no se adecúan a las exigencias de la protección del consumidor ya sea por su clara incompatibilidad o por su insuficiencia técnica, o incluso, ante la existencia de lagunas jurídicas que es obligatorio colmar. Máxime por cuanto se trata de garantizar la eficacia de disposiciones y objetivos de interés público para la Unión, cuya última ratio es proteger a un grupo vulnerable, los consumidores, que es esencial para el buen funcionamiento del mercado interior ${ }^{111}$, y la propia tutela de derecho reconocido en el art. 47 de la CDFUE ${ }^{112}$.

De ahí la radicalidad de la jurisprudencia Aziz, antes citada, confirmada posteriormente al facultar al juez nacional que conoce de una ejecución hipotecaria para adoptar medidas cautelares, en particular, la suspensión de la ejecución, cuando el entorno normativo interno no le permite ni examinar, ya sea de oficio o a instancia del consumidor, el carácter abusivo de una cláusula del contrato del que se deriva la deuda reclamada, ni la propia adopción de estas medidas ${ }^{113}$.

El empoderamiento de los órganos jurisdiccionales de los Estados miembros por la acción pretoriana del TJ resulta aún más transcendental transcurridos veinte años de vigencia de la jurisprudencia Borelli ${ }^{114}$.

110 Véase, por ejemplo, la sentencia Unicaja Banco y Caixabank, EU:C:2015:21, apdos. 28 y 29 y jurisprudencia que se cita. Similarmente, tampoco están obligados a suplir íntegramente la absoluta pasividad del consumidor interesado en la anulación de una cláusula contractual controvertida; véase la sentencia del TJ Asturcom, C-40/08, EU:C:2009:615, apdo. 47.

111 Véase, en este sentido, Verica TRSTENJAK y Erwin BEYSEN, «European Consumer Protection Law: Curia Semper Dabit Remedium?», Common Market Law Review, vol. 48, 1, 2011, pp. 95-124.

112 Véase, por ejemplo, la sentencia del TJ Banif, C-472/11, EU:C:2013:88, apdo. 29, y jurisprudencia que se cita. Igualmente, la sentencia del TJ Otis NV, C-199/11, EU:C:2012:684, apdos. 46-49, y jurisprudencia que se cita; etc.

113 Véase la sentencia del TJ Banco Popular Español y, Banco de Valencia, C-537/12 y C-116/13, EU:C:2013:759, apdos. 54-60.

114 Véase la sentencia del TJ Oleificio Borelli, C-97/91, EU:C:1992:491, apdos. 13 y 14, en los que estableció la competencia de los órganos jurisdiccionales nacionales para pronunciarse sobre la adecuación a un acto de derecho comunitario de un acto preparatorio interno, fundamento de la decisión final controvertida, que, a falta de previsiones normativas, quedaba privado de control jurisdiccional, equiparándolo a 
Por consiguiente, el juez nacional de medidas cautelares se convierte en un instrumento clave para la aplicación eficiente de las disposiciones en cuestión, oscilando aquí su función jurisdiccional entre el deber de cumplir y hacer cumplir las obligaciones que expresamente ha determinado el TJ a cargo de todos los órganos jurisdiccionales que entiendan de un procedimiento sobre esta materia y la mera facultad para el ejercicio de sus prerrogativas.

Dentro del conjunto de obligaciones que atañen al juez nacional de medidas cautelares pueden incluirse, entre otras, la de suspender un procedimiento de ejecución hipotecaria aunque sólo conozca del proceso declarativo sobre el carácter abusivo de una cláusula del contrato cuyo incumplimiento desencadenó el procedimiento para la ejecución controvertida ante otro órgano jurisdiccional ${ }^{115}$; realizar una intervención positiva para apreciar de oficio el carácter abusivo de una cláusula contractual controvertida ${ }^{116}$ y para recalificar, en su caso, el fundamento jurídico invocado para sustentar su invalidez, así como para apreciar la validez de un acto jurídico en relación con las normas internas de orden público si afecta a la salvaguardia de los derechos que el ordenamiento de la Unión confiere al consumidor ${ }^{117}$; dejar sin aplicación

estos efectos con los actos definitivos adoptados por las autoridades nacionales. Un análisis en Eduardo GARCÍA DE ENTERRÍA, «La ampliación de la competencia de las jurisdicciones contencioso-administrativas nacionales por obra del Derecho Comunitario. Sentencia Borelli de 3 de diciembre de 1992 del TJ y el art. 5 CEE», Revista Española de Derecho Administrativo, núm. 78, 1993, pp. 317-324.

115 Véase la sentencia del TJ Sánchez Morcillo, C-169/14, EU:C:2014:2099, apdos. $42-$ 51 y jurisprudencia que se cita. A mayor abundamiento, deberá apreciar de oficio la contrariedad de una cláusula arbitral con las disposiciones de orden público aquí relevantes, y apreciar de oficio su carácter abusivo, si conoce de una demanda de ejecución forzosa del laudo arbitral controvertido, sentencia Asturcom, EU:C:2009:615, apdo. 53.

116 Sentencia del TJ Finanmadrid y Albán Zambrano, C-49/14, EU:C:2016:98, apdos. 45-47 y 52-55, y jurisprudencia que se cita. Véanse, igualmente las conclusiones del Abogado General Szpunar en el asunto Finanmadrid, EU:C:2015:746, puntos 43-77 y jurisprudencia que se cita en las notas correspondientes.

117 Sentencia del TJ Jörös, C-397/11, EU:C:2013:34, apdos. 27-30 y 38, y jurisprudencia que se cita. Al analizar el posible carácter abusivo de una cláusula contractual controvertida el juez nacional podrá también dilucidar acerca de la exactitud y la veracidad de sus términos, así como sobre la inclusión de ciertas informaciones exigidas por las disposiciones del derecho de la Unión relevantes al caso; véase la sentencia del TJ Bucura, C-348/14, EU:C:2015:447, apdos. 48-58 y 61-63, y jurisprudencia que se cita. Asimismo, podrá verificar la existencia de otros requisitos acerca de la naturaleza del contrato controvertido, tales como si el contratante de que se trata tiene objetivamente un carácter de consumidor, o acerca del ámbito de aplicación de 
una cláusula contractual abusiva para que no produzca efectos vinculantes al consumidor, salvo que ello suponga algún perjuicio para este ${ }^{118}$, y determinar, en su caso, si el contrato puede subsistir sin dicha cláusula ${ }^{119}$, habida cuenta de que el ejercicio de esta prerrogativa no dependerá de que la cláusula abusiva se aplique o no en la práctica ${ }^{120}$; hacer que se recalculen las cantidades debidas en virtud de una cláusula de un contrato de préstamo hipotecario que ha fijado unos intereses de demora con un tipo abusivo, sin perjuicio de que el propio juez pueda decidir su inaplicación ${ }^{121}$, etc.

En lo concerniente a la posibilidad de ejercer facultades atribuidas por el derecho de la Unión debe reseñarse la de sustituir una cláusula abusiva por una disposición supletoria de derecho nacional en aquellos supuestos en los que la declaración de nulidad de dicha cláusula le obligara a anular el contrato en su totalidad, quedando expuesto el consumidor a una penalización ${ }^{122}$.

\section{LA TUTELA DEL ORDEN PÚBLICO Y LA COOPERACIÓN JUDICIAL EN EL ESPACIO DE LIBERTAD, SEGURIDAD Y JUSTICIA}

En otro orden de cosas, y como ya reseñamos anteriormente, se ha consolidado una jurisprudencia que establece que la autonomía de la que disfrutan los órganos jurisdiccionales nacionales que entienden sobre el fondo de un asunto debe conjugarse con la necesaria aplicación de los principios de

dicho contrato; véase en este sentido el auto del TJ Tarcau, C-74/15, EU:C:2015:772, apdos. 27-30 y jurisprudencia que se cita.

118 Véase, por ejemplo, el auto del TJ Ibercaja y Cortés González, C-613/15, EU:C:2016:195, apdos. 37-42, y jurisprudencia que se cita.

119 Véase, por ejemplo, el auto Banco Bilbao Vizcaya Argentaria, EU:C:2015:397, apdo. 33 y jurisprudencia que se cita; la sentencia Bucura, EU:C:2015:447, apdos. 64-65 y jurisprudencia que se cita, etc.

120 Véase el auto Banco Bilbao Vizcaya Argentaria, EU:C:2015:397, apdos. 50-54.

121 Véase la sentencia Unicaja Banco y Caixabank, EU:C:2015:21, apdos. 40-42. Habida cuenta de la importancia del interés público en el que se basa la protección que las disposiciones que nos ocupan otorga a los consumidores, la existencia de un control de oficio respecto de una o varias cláusulas contractuales no limitaría la obligación del juez nacional de examinar de oficio el carácter abusivo de las demás en una fase posterior del procedimiento; véase, en este sentido, las conclusiones del Abogado General Szpunar en el asunto Banco Primus, EU:C:2016:69, puntos 48-49.

122 Véanse, entre otras, la sentencia Kásler y Rábai, EU:C:2014:282, apdos. 82 a 84; y la sentencia del Banco Bilbao Vizcaya Argentaria, EU:C:2015:397, apdo. 38 y jurisprudencia que se cita. 
confianza recíproca y reconocimiento mutuo cuando se trata de reconocer y/o ejecutar las decisiones judiciales provenientes de otros Estados miembros ${ }^{123}$.

La consagración de los mencionados principios en numerosos instrumentos vinculantes de derecho derivado que regulan los ámbitos más relevantes de la cooperación judicial europea corrobora su carácter imperativo y la necesidad de garantizar la protección de su efecto útil mediante una aplicación uniforme en el territorio de los Estados miembros ${ }^{124}$.

De conformidad con lo previsto en tales disposiciones y con lo establecido en cierta doctrina relevante del TJ a la que ha hemos hecho referencia, puede precisarse la función del juez nacional de medidas cautelares cuando tutela principios consagrados en este ámbito normativo que reúnen características inherentes al orden público de la UE.

Así, por ejemplo, la jurisprudencia que establece que, conforme al principio de confianza mutua, los motivos de denegación del reconocimiento deben limitarse al mínimo necesario ${ }^{125}$, adquiere una imperatividad radical al tratarse

123 Véase la sentencia del TJ Openbaar Ministerie/A., C-463/15 PPU, EU:C:2015:364, apdos. 23-31 y jurisprudencia que se cita. Ello no prejuzga la salvaguardia del principio de autonomía que se reconoce al juez nacional cuando ejerce el control acerca de su competencia sobre un litigio; véase la sentencia del TJ Kolassa, C-375/13, EU:C:2015:37, apdos. 58-65, y jurisprudencia que se cita. Igualmente, las conclusiones del Abogado General Szpunar en el asunto Kolassa, EU:C:2014:2135, puntos 68-80.

${ }^{124}$ Así, por ejemplo, el considerando octavo, el apdo. primero del art. 20 y el apdo. primero del art. 21 del Reglamento (CE) 861/2007 del Parlamento Europeo y del Consejo de 11 de julio de 2007, por el que se establece un proceso europeo de escasa cuantía (DO L 199 de 31.7.2007, p. 1), y el considerando vigésimo séptimo y el art. 19 del Reglamento (CE) 1896/2006 del Parlamento Europeo y del Consejo de 12 de diciembre de 2006, por el que se establece un proceso monitorio europeo (DO L 399 de 30.12.2006, p. 1). Ambos reglamentos han sido modificados por el Reglamento (UE) 2015/2421 del Parlamento Europeo y del Consejo de 16 de diciembre de 2015 (DO L 341 de 24.12.2015, p. 1). Asimismo, el considerando tercero, el apdo. primero del art. 36, y, el art. 29 del Reglamento (UE) 1215/2012, antes citado; el considerando segundo y el apdo. primero del art. 21 del Reglamento (CE) 2201/2003 del Consejo de 27 de noviembre de 2003, relativo a la competencia, el reconocimiento y la ejecución de resoluciones judiciales en materia matrimonial y de responsabilidad parental, por el que se deroga el Reglamento (CE) 1347/2000 (DO L 338 de 23.12.2003, p. 1). Considerandos cuarto y quinto del Reglamento (CE) 4/2009 del Consejo de 18 de diciembre de 2008 relativo a la competencia, la ley aplicable, el reconocimiento y la ejecución de las resoluciones y la cooperación en materia de obligaciones de alimentos (DO L 7 de 10.1.2009, p. 1); etc.

125 Véase las sentencias del TJ Povse, C-211/10 PPU, EU:C:2010:400, apdo. 40; y Rinau, C-195/08 PPU, EU:C:2008:406, apdo. 50; etc. Similarmente, y en lo que con- 
de la protección del interés del menor ${ }^{126}$, que es un principio encuadrable en el orden público supranacional ${ }^{127}$. Consiguientemente, los órganos jurisdiccionales concernidos quedan sujetos por el deber de estricta vigilancia para proteger objetivamente el interés del menor frente a cualquier tipo de actuación de las partes que, a la búsqueda de sus intereses subjetivos, pueda perjudicarle.

Ello incluye, muy especialmente, la restricción al ejercicio de sus competencias jurisdiccionales si fuera menester. La doctrina del TJ no deja dudas al respecto cuando establece que, salvo en supuestos de violaciones manifiestas de normas jurídicas esenciales o de derechos fundamentales reconocidos en el ordenamiento jurídico de un Estado miembro, un órgano jurisdiccional de dicho Estado que se considera competente para resolver sobre la custodia de un menor no puede denegar el reconocimiento de la resolución de un órgano jurisdiccional de otro Estado miembro que ha resuelto sobre ella ${ }^{128}$.

A mayor abundamiento, y teniendo en cuenta que el carácter imperativo de las normas de competencia jurisdiccional del Reglamento (CE) 2201/2003 del Consejo, antes citado, persigue proteger el interés superior del menor, las excepciones a la regla general establecida en su art. 8, según la cual, corresponde la competencia en materia de responsabilidad parental al órgano jurisdiccional del Estado miembro en que resida habitualmente el menor en el momento en que se presenta el asunto ante dicho órgano, deben interpretarse de manera restrictiva ${ }^{129}$.

cierne al ámbito matrimonial, el Tribunal ha interpretado las disposiciones relevantes del citado Reglamento (CE) 2201/2003, del Consejo, estableciendo que cuando el demandado no tiene su residencia habitual en su Estado miembro del que no es nacional, el juez nacional de dicho Estado no puede fundar su competencia en su derecho nacional para resolver una demanda de divorcio si los órganos jurisdiccionales de otro Estado miembro son competentes con arreglo al Reglamento; véase la sentencia del TJ Kerstin Sundelind, C-68/07, EU:C:2007:740, apdos. 18-19 y 22-28.

126 Véanse, por ejemplo, los considerandos duodécimo y décimo tercero, y la letra a) del art. 23 del Reglamento (CE) 2201/2003 del Consejo, antes citado.

127 En este sentido es calificado como "principio esencial» o "principio superior» por el Abogado General Jääskinen en sus conclusiones presentadas sobre el asunto Purrucker, C-296/10, EU:C:2010:578, punto 103.

128 Véase la sentencia del TJ P/Q, C-455/15 PPU, EU:C:2015:763, apdos. 35-46 y 53. Consiguientemente, controla minuciosamente si la normativa interna relevante aún derivada de la eficaz cooperación de carácter bilateral o multilateral en beneficio del bienestar del menor, es compatible con las disposiciones relevantes del derecho de la UE; véase la sentencia del TJ C, C-435/06, EU:C:2007:714, apdos. 58-62 y 74-76.

129 Véanse las conclusiones del Abogado General Bot en el asunto Deticek, C-403/09 PPU, EU:C:2009:762, puntos 66-76. 
Esta obligación cobra plena razón de ser a la luz de lo dispuesto en el art. 10 del citado Reglamento sobre el traslado o retención ilícita de un menor, con la interdicción absoluta del forum shopping.

De conformidad con todo ello, el TJ ha establecido en su jurisprudencia que no permite que un órgano jurisdiccional de un Estado miembro adopte medidas provisionales o cautelares que otorguen la custodia de un menor que se encuentra en el territorio de dicho Estado a uno de los progenitores, cuando un órgano jurisdiccional de otro Estado miembro, competente en virtud del mencionado Reglamento del fondo del litigio sobre la custodia del menor, ya ha determinado concederla provisionalmente al otro progenitor, y esta resolución judicial ha sido declarada ejecutiva en el territorio del primer Estado miembro ${ }^{130}$.

Resulta muy didáctica la jurisprudencia en cuestión, establecida en el asunto Deticek, a los efectos de fijar los criterios a los que debe atenerse el juez nacional de medidas cautelares que actúe sobre la base de lo previsto en el apartado primero del art. 20 del citado Reglamento. Esta disposición autoriza a los órganos jurisdiccionales de un Estado miembro en que se encuentre el menor para adoptar medidas provisionales o cautelares previstas en su legislación nacional, aun cuando en virtud del citado Reglamento la competencia sobre el fondo corresponda a un órgano jurisdiccional de otro Estado miembro.

En este sentido, el Tribunal advierte que la adopción de esas medidas provisionales o cautelares sólo puede tener lugar cuando concurran tres requisitos acumulativos: deben ser urgentes, deben adoptarse frente a personas o bienes presentes en el Estado miembro en el que ejerza su competencia el órgano jurisdiccional concernido, y deben tener carácter provisional, es decir, dejarán de aplicarse cuando el órgano jurisdiccional del Estado miembro competente sobre el fondo haya adoptado las medidas apropiadas. En el bien entendido que, al constituir una excepción al sistema de competencia previsto en el citado Reglamento, los órganos jurisdiccionales concernidos deberán interpretar el ejercicio de esta facultad de modo estricto ${ }^{131}$.

No obstante, el reconocimiento de la facultad de adoptar medidas cautelares por los jueces nacionales está prevista expresamente en diversas disposi-

130 Véase la sentencia Deticek, EU:C:2009:810, apdos. 60-61.

131 Véase la sentencia Deticek cit., EU:C:2009:810, apdo. 38-40 y jurisprudencia que se cita. Entre los autores que han analizado esta sentencia del Tribunal de Justicia, véanse: Marta REQUEJO ISIDRO, «El art. 20 del Reglamento (CE) número 2201/2003 ante el TJCE», Diario La Ley, año 2010, núm. 7479, pp. 1-6; y, Elena RODRÍGUEZ PINEAU, «Medidas provisionales en el Reglamento Bruselas II bis», Diario La Ley, año 2011, núm. 7061, pp. 11-16. 
ciones normativas que regulan la cooperación judicial en el seno de la $\mathrm{UE}^{132}$, además de en el mencionado art. 20 del Reglamento (CE) 2201/2003 ${ }^{133}$.

Especialmente esclarecedora sobre la tipología y los efectos de estas medidas resulta la jurisprudencia sentada por el $\mathrm{TJ}$ en el asunto $\mathrm{A}^{134}$. Dado que la normativa relevante de la Unión Europea no prevé qué clase de medidas han de aplicarse, se respeta la competencia de los Estados miembros tanto para establecerlas como para fijar las modalidades procesales para su ejecución establecidas para preservar el interés superior del menor; por lo que su carácter vinculante se desprenderá de la normativa interna de que se trate ${ }^{135}$. También se determina en la citada jurisprudencia que, aunque la normativa europea no establece la obligación de los órganos jurisdiccionales nacionales que adopten medidas provisionales o cautelares del traslado de los autos a los de otro Estado miembro competente después de haber aplicado dichas medidas, deberán, no obstante, informar de ellas a este último, directamente o por conducto de la autoridad central correspondiente, siempre que la protección del interés superior del menor lo exija ${ }^{136}$.

Más controvertida resulta la cuestión de discernir acerca de la validez y los efectos de las medidas cautelares relativas a la custodia exclusiva de un menor adoptadas por un órgano jurisdiccional de un Estado miembro con anterioridad a la interposición de una demanda sobre el fondo con el mismo objeto ante un órgano jurisdiccional de otro Estado miembro, cuando no

132 Por ejemplo, los arts.14 y 36 del Reglamento (CE) 4/2009 del Consejo, antes citado; los arts. 35 y 40 del Reglamento (CE) 1215/2012 del Parlamento Europeo y del Consejo, antes citado; etc.

133 Pero el acervo jurisprudencial que interpreta el alcance de estas últimas ha adquirido un peso específico reseñable habida cuenta de la necesidad de garantizar el respeto al principio fundamental de la tutela del interés superior del menor que persiguen las normas sobre competencia jurisdiccional del citado Reglamento con carácter general. Así, por ejemplo, en lo concerniente a la determinación de la competencia jurisdiccional sobre un asunto encausado en dos jurisdicciones de dos Estados miembros y en el que una de ellas había adoptado diversas medidas cautelares a instancia de la parte demandante, se ha establecido que se considera competente a la jurisdicción que entendió inicialmente sobre el fondo de la misma aunque hubiera decidido adoptar medidas de suspensión del procedimiento a instancia de la demandante sobre las que no tuvo conocimiento la parte demandada; véase la sentencia del TJ P/M, C-507/14, EU:C:2015:512, apdos. 37-43.

134 Sentencia del TJ A cit., C-523/07, EU:C:2009:225.

135 Sentencia A cit., EU:C:2009:225, apdos. 49-52.

136 Ibid., apdos. 53-64. Véanse, igualmente, las conclusiones de la Abogado General Kokott en el asunto A, EU:C:2009:39, puntos 70-80. 
existe ningún indicio que pruebe la posible sustracción ilícita del menor, los dos litigios enfrenten a las mismas partes y ambos órganos son aparentemente competentes para conocer sobre dicho asunto.

El TJ ha dilucidado esta situación en la jurisprudencia establecida en los asuntos Purrucker (I) ${ }^{137}$ y (II) ${ }^{138}$. Aunque la argumentación del Tribunal parte del principio de prevalencia de las disposiciones relevantes del citado Reglamento (CE) 2201/2003 sobre las previsiones del derecho interno y sobre la mayoría de los convenios internacionales de la materia, así como del carácter vinculante de los principios de reconocimiento mutuo y de confianza mutua a la hora de fijar el reparto de competencias entre los órganos jurisdiccionales de los Estados miembros concernidos ${ }^{139}$, el elemento que resulta determinante es el de la identificación de la norma que habilita al juez nacional para adoptar las medidas cautelares controvertidas, ya que si es de naturaleza internacional podría también conocer sobre el fondo del asunto ${ }^{140}$.

Pero, al no presentarse con claridad por el órgano jurisdiccional concernido los fundamentos de esta posible atribución de competencia, el TJ circunscribe la adopción de las medidas controvertidas al ámbito de aplicación del citado art. 20 de dicho Reglamento, con las consiguientes limitaciones y condicionantes que ello supone y que ya han sido puestos de manifiesto anteriormente ${ }^{141}$.

En consecuencia, establece que, aunque dichas medidas no gozan del reconocimiento y ejecución fuera del territorio del Estado miembro en que se adoptan —art. 21 y siguientes, y art. 46 del citado Reglamento (CE) 2201/2003-, ello no impide que puedan adquirir ciertos efectos en otro Estado miembro derivados de su propia normativa interna o de otros instrumentos de naturaleza internacional ${ }^{142}$. Subraya en este sentido el Tribunal que, con independencia de que las medidas sean adoptadas por un juez competente o no sobre el fondo del asunto, la protección del interés del menor exige que la persona afectada por las mismas pueda recurrirlas ante un órgano jurisdiccional de otro Estado miembro concernido, a los efectos de rebatir la competencia sobre el fondo que reclama para sí el órgano jurisdiccional que las adoptón ${ }^{143}$.

137 Sentencia del TJ Purrucker, C-256/09, EU:C:2010:437.

138 Sentencia del TJ Purrucker, C- 296/10, EU:C:2010:665.

139 Véase sentencia Purrucker, C-256/09, cit., apdos. 69-73.

140 Ibid., apdos. 65-67.

141 Ibid., apdos. 77-81.

142 Ibid., apdos. 82-92

${ }^{143}$ Ibid., apdos. 97-98, y jurisprudencia que se cita. Esta sentencia ha sido objeto de algún análisis doctrinal crítico que disiente, entre otros aspectos, acerca de la fundamen- 
Una situación diferente se plantea cuando existen indicios de que el primer órgano jurisdiccional ante el que se solicitaron las medidas cautelares pudiera ser competente sobre el fondo del asunto, ya que ello obligaría al órgano jurisdiccional ante el que se plantea posteriormente la demanda sobre el fondo a suspender el procedimiento (apartado segundo del art. 19 del citado Reglamento 2201/2003), y a examinar si existen fundamentos para inhibirse a favor del otro órgano jurisdiccional. Pero la salvaguarda del interés del menor adquiere también en estas circunstancias una relevancia especial al establecerse que, si fuera menester, el segundo órgano jurisdiccional podrá adoptar las medidas provisionales necesarias de conformidad con lo previsto en el art. 20 del Reglamento antes citado ${ }^{144}$.

Conviene subrayar, en suma, la importancia del papel del juez nacional de medidas cautelares cuando utiliza sus prerrogativas en el ámbito que nos ocupa, habida cuenta de la ambivalencia de las resoluciones sobre la responsabilidad parental que, si bien generalmente gozan de carácter constitutivo, suelen carecer del efecto negativo de la fuerza de cosa juzgada para que puedan ser modificadas si lo exige el interés del menor ${ }^{145}$.

tación sobre el art. 20 del citado Reglamento (CE) 2201/2003 de la falta de efectos extraterritoriales de las medidas controvertidas, y, de la ausencia de un análisis sobre la capacidad de esta disposición para atribuir la propia competencia a los órganos jurisdiccionales internos para adoptar tales medidas. Tampoco queda claro, según se critica, si el tribunal que conozca sobre el fondo puede adoptar medidas cautelares con alcance extraterritorial; véase, Ana Paloma ABARCA JUNCO y Miguel GÓMEZ-JENE, «Medidas provisionales y Reglamento Bruselas II (a propósito de la sentencia del TJUE en el asunto Purrucker), en Carlos ESPLUGUES MOTA, Guillermo PALAO MORENO y Manuel Alejandro PENADÉS FONS (coords.), Nuevas fronteras del derecho de la Unión Europea: Liber amicorum: José Luis Iglesias Buhigues, Tirant lo Blanch, Valencia, 2012, pp. 149-162, especialmente 154-155.

${ }^{144}$ Véase la sentencia Purrucker, C- 296/10, cit., apdos. 78-80. La protección del interés del menor está presente también en el marco de las actividades desarrolladas por el órgano jurisdiccional que entiende del asunto en segundo lugar al precisar el Tribunal que, si tras plantear las preguntas correspondientes al primer órgano jurisdiccional, no recibe respuesta transcurrido un plazo razonable de espera, podrá continuar con el examen de la demanda sobre el fondo correspondiendo fijar la determinación del plazo razonable al segundo órgano jurisdiccional en función «ante todo» del interés del menor, tomando en cuenta además el hecho de que se trate de «un menor de corta edad»; véase la sentencia Purrucker, C- 296/10, cit. apdos. 82-83.

145 Véanse las conclusiones del Abogado General Jääskinen en el asunto Purrucker, C296/10, EU:C:2010:578, puntos 71 y 72. 


\section{CONCLUSIONES}

La tutela de las disposiciones y principios del orden público y del interés público de la Unión Europea por el juez nacional de medidas cautelares tiene lugar en situaciones en las que ante la inadecuación del entorno normativo interno de que se trate, deberá garantizar el efecto útil de las mismas y asegurar la eficacia de la resolución que finalmente se adopte sobre el fondo del litigio.

No obstante, el juez nacional de medidas cautelares dispone, en principio, de mayor discrecionalidad para apreciar la oportunidad de decretarlas, habida cuenta de que no tiene que cuestionar aquí la legalidad de actos internos adoptados en ejecución de normas de la Unión, ni de su inaplicación por considerar que están estas presuntamente viciadas de nulidad, por lo que su adopción no quedaría sujeta a los estrictos requisitos y condiciones establecidas por el TJ en la jurisprudencia sobre los asuntos Zuckerfabrik, y Atlanta, antes citada.

Al tratarse de disposiciones y principios que gozan, en su calidad de elementos fundamentales del sistema jurídico de la Unión, de la primacía de aplicación, la tutela cautelar por los órganos jurisdiccionales internos debe adecuarse al principio de efectividad del derecho de la Unión, a cuyos efectos, aunque apliquen la tipología cautelar y actúen de conformidad con los procedimientos previstos en el ordenamiento nacional, deberán respetar también diversas reglas establecidas a nivel supranacional que ya se han reseñado.

Ese conjunto de reglas se refiere a cualquier actuación de los jueces nacionales cuando se les demanda tutelar cautelarmente los derechos y libertades reconocidos en el ordenamiento de la UE, y configuran un «régimen general» mediante el cual se articula la atribución de esta facultad a los órganos jurisdiccionales internos por el TJ.

Ciertamente y dado que dicho régimen de atribución se enmarca en el diálogo cooperativo entre las jurisdicciones internas y supranacional, el juez nacional de medidas cautelares preserva un ámbito relevante de discrecionalidad, tal y como reconoce el propio TJ, pero también derivado de la normativa y la práctica interna en materia cautelar.

Sin embargo, este marco de actuación podrá verse afectado si la medida cautelar tiene como finalidad tutelar las disposiciones y principios que nos ocupan, dado que el juez nacional deberá seguir las «reglas específicas» las «atribuciones singularizadas» establecidas a los efectos por el TJ.

Como ya se ha reseñado, la aplicación interna de las disposiciones y principios de orden público y de interés público del derecho de la UE debe conformarse al principio de primacía, actuando el juez nacional de medidas cautelares como un auténtico juez de la Unión, ya sea para integrar lagunas jurídicas, inaplicar normas nacionales contrarias a las mismas o sustituirlas por otras que sean adecuadas, según los casos. Bajo ninguna circunstancia, el 
juez nacional de medidas cautelares podrá cuestionar el carácter como tales de disposiciones o principios de orden público o de interés público de la UE, una vez que han sido consagradas por el TJ, si no que su misión es la de coadyuvar al pleno desarrollo de la implementación a nivel interno, proteger su «efecto útil» en aras del desarrollo de un justo proceso.

Si se trata, por ejemplo, de garantizar la plena aplicación de los arts. 101 TFUE y 102 TFUE, disposiciones de orden público que gozan de efecto directo vertical y horizontal, la imperatividad inherente a las mismas que exige al juez nacional la adopción de una medida cautelar que inaplique una norma interna incompatible, queda reforzada mediante el reconocimiento de la facultad de decretar, además, cuantas medidas resulten pertinentes para reparar los daños y perjuicios injustamente causados por la violación de dichas disposiciones al demandante.

Mayor calado jurídico suponen, a mi entender, los criterios establecidos por el Tribunal con relación al ejercicio de la potestad cautelar por los jueces nacionales cuando tutelan disposiciones de interés público de directivas sobre protección de los consumidores, dado que estas carecen en cualquier circunstancia de efecto directo horizontal. Junto con el reconocimiento de la facultad de adoptar medidas que suspendan la ejecución de actos internos que no sean conformes a las citadas disposiciones, cuando las normas nacionales no permitan su adopción, o de sustituir una cláusula abusiva de un contrato por una disposición supletoria de derecho interno, el Tribunal ha establecido cierta doctrina que determina un conjunto de obligaciones cuya última razón de ser es proteger a un grupo vulnerable, los consumidores, $\mathrm{y}$ al propio funcionamiento del mercado interior.

Precisamente, la necesidad de proteger el interés del menor, altamente vulnerable, que es un principio encuadrable en el orden público supranacional, ha generado una jurisprudencia mediante la cual el TJ clarifica diversos aspectos relativos a la adopción de medidas cautelares por los órganos jurisdiccionales internos de conformidad con lo previsto en las disposiciones de algunos reglamentos de la Unión Europea sobre cooperación judicial.

La atribución de las competencias cautelares a los jueces nacionales mediante la relevante doctrina del TJ que hemos analizado, reúne ciertas características que hacen prever su futuro desarrollo a otros ámbitos del derecho de la Unión, ya que se trata de una jurisprudencia dinámica que establece la atribución de la competencia en materia cautelar progresivamente, con una elevada precisión técnica, y muy rigurosa a la hora de preservar el justo equilibrio entre la necesaria protección del efecto útil de las disposiciones y principios supranacionales en cuestión y la autonomía de los órganos jurisdiccionales internos que deben decidir acerca de su aplicación, dado que a estos les corresponde garantizar en todo caso el buen proceso de conformidad con el respeto del derecho de la tutela judicial efectiva. 